\title{
Comprehensive Numerical Assessment of Rotorcraft Vibration and Noise Control Using Microflaps
}

\author{
Ashwani K. Padthe, $*$ Peretz P. Friedmann,, and Miang H. Chia \\ University of Michigan, Ann Arbor, Michigan 48109 \\ and \\ Li Liuㅗㅛ \\ The Boeing Company, Mesa, Arizona 85215 \\ DOI: $10.2514 / 1 . C 033448$
}

\begin{abstract}
Active Gurney flaps, or microflaps, are studied to determine their effectiveness in reducing noise and vibration in rotorcraft as well as improving rotor performance. The effectiveness of the microflap is examined using a comprehensive rotorcraft simulation code. The aerodynamic properties of the microflap are modeled using a nonlinear computational-fluid-dynamics-based reduced-order aerodynamic model that takes into account unsteadiness, compressibility, and time-varying freestream effects. Active control studies are conducted on a hingeless rotor configuration resembling the Messerschmitt-Bölkow-Blohm BO-105, using various spanwise microflap configurations, including single, dual, and segmented five-microflap configurations. Results indicate that the microflap is capable of substantial reductions in blade-vortex interaction noise ranging from 3 to $6 \mathrm{~dB}$. Vibration reduction ranging from 70 to $90 \%$ is also demonstrated. The effect of vibration reduction on noise and vice versa is also examined, and it was found that reduction in one objective is accompanied by an increase in the other, a trend also observed when using other active control approaches. Finally, the microflap is considered for combined vibration reduction and performance enhancement at a high-speed cruise flight condition. The results clearly indicate that the microflaps are very effective for both noise and vibration reduction in helicopters, and they also have potential for rotor performance enhancement.
\end{abstract}

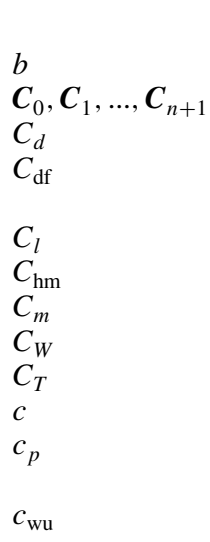
$\boldsymbol{D}, \boldsymbol{E}, \boldsymbol{R}$
$D_{0}, D_{1}$
$E I_{\eta \eta}, E I_{\zeta \zeta}$ $e$
Nomenclature

$=$ airfoil semi-chord $=c / 2$

$=$ rational function coefficient matrices

$=$ total drag coefficient

$=$ parasitic drag coefficient of the fuselage

$=$ lift coefficient

$=$ hinge moment coefficient

$=$ moment coefficient

$=$ helicopter weight coefficient

$=$ rotor thrust coefficient

$=$ airfoil chord

$=$ pressure coefficient on the airfoil surface

$=$ scalar used in the auto-weighting approach

$=$ matrices defined in the RFA model

$=$ generalized flap motions

$=$ principal bending stiffness of the blade cross-section

$=$ blade root offset from the center of rotation
Presented as Paper 2011-1873 at the 52nd AIAA/ASME/ASCE/AHS/ASC Structures, Structural Dynamics, and Materials Conference, Denver, CO, 47 April 2011; received 16 March 2015; revision received 2 October 2015; accepted for publication 4 October 2015; published online 22 December 2015. Copyright ( 2015 by Ashwani K. Padthe, Peretz P. Friedmann, Miang H. Chia, and Li Liu. Published by the American Institute of Aeronautics and Astronautics, Inc., with permission. Copies of this paper may be made for personal and internal use, on condition that the copier pay the per-copy fee to the Copyright Clearance Center (CCC). All requests for copying and permission to reprint should be submitted to CCC at www.copyright.com; employ the ISSN 0021-8669 (print) or 1533-3868 (online) to initiate your request.

*Research Investigator, Department of Aerospace Engineering. Member AIAA.

${ }^{\dagger}$ François-Xavier Bagnoud Professor, Department of Aerospace Engineering. Fellow AIAA.

${ }^{\ddagger}$ Ph.D. Candidate, Department of Aerospace Engineering. Member AIAA.

${ }^{\S}$ Structural Analysis Engineer. Member AIAA.

$F_{\mathrm{HX} 4}, F_{\mathrm{HY} 4}, F_{\mathrm{HZ} 4}$
$f$
$G$
$G J_{b}$
$H$
$\boldsymbol{h}$
$h$
$I_{\mathrm{MB} 2}, I_{\mathrm{MB} 3}$
$k$
$L_{b}$
$L_{c}$
$M$
$M_{b}$
$M_{\mathrm{HX} 4}, M_{\mathrm{HY} 4}, M_{\mathrm{HZ} 4}$
$M_{\mathrm{Hz} 1}$
$N_{b}$
$N_{H 06}, N_{H 07}, \cdots, N_{H 17}$
$N_{\delta}$
$n_{L}$
$P_{R}$
$\bar{p}$

$Q$

$\boldsymbol{Q}_{z}$

$Q$

$R$

$\bar{s}$

$\hat{\boldsymbol{T}}_{\mathrm{LS}_{k}}$

$T$

$\bar{t}$

u
$=$ nondimensional $4 /$ rev hub shears

$=$ generalized load vector

$=$ Laplace transform of $f(\bar{t}) U(\bar{t})$

$=$ torsional stiffness of the blade crosssection

$=$ Laplace transform of $h(\bar{t})$

$=$ generalized motion vector

$=$ airfoil plunge coordinate

$=$ principal mass moments of inertia of the blade cross-section

$=$ reduced frequency $=\omega b / U$

$=$ blade length

$=$ spanwise dimension of blade segment with microflap

$=$ mach number

$=$ blade mass

$=$ nondimensional $4 / \mathrm{rev}$ hub moments

$=$ total yawing moment about the hub

$=$ number of rotor blades

$=6$ th -17 th harmonic components of BVI noise

$=$ number of control surfaces

$=$ number of lag terms

$=$ rotor power

$=$ nondimensional surface pressure distribution

$=$ aerodynamic transfer function matrix

$=$ weighting matrix for plant output

$=$ approximation of $\boldsymbol{Q}$

$=$ blade radius

= Laplace variable

$=$ nondimensional Laplace variable $=$ $s b / U$

$=$ least squares estimate of $T$

$=$ sensitivity matrix

$=$ time

$=\quad$ reduced time $=\frac{1}{b} \int_{0}^{t} U(\tau) d \tau$

$=$ freestream velocity, time-dependent

$=$ control input vector 
V $v, \Delta v, \Delta v_{a}$

$W_{0}, W_{1}$
$W_{\alpha}$
$\boldsymbol{w}$
$X_{A}$
$X_{\mathrm{FA}}, Z_{\mathrm{FA}}$

$X_{\mathrm{FC}}, Z_{\mathrm{FC}}$

$X_{\mathrm{Ib}}$

$X_{I I b}$

$X_{t}, Z_{t}$

$x_{c}$

$x(t)$

$z$

$\alpha$

$\alpha_{R}$

$\beta_{p}$

$\delta$

$\delta_{\mathrm{NC}}, \delta_{\mathrm{NS}}$

$\gamma$

$\gamma_{n}$

$\mu$

$\Omega$

$\omega$

$\bar{\omega}$

$\psi$

$\sigma$

$\theta_{\mathrm{tw}}$
$\omega_{F}, \omega_{L}, \omega_{T}$

$=$ freestream velocity for the airfoil

$=$ components of the local velocity at any point on the surface of the airfoil due to thickness, camber, and angle of attack, respectively

$=$ generalized airfoil motions

$=$ relative weighting parameter

$=$ disturbance

$=$ offset between the aerodynamic center and the elastic axis

$=$ longitudinal and vertical offsets between rotor hub and helicopter aerodynamic center

$=$ longitudinal and vertical offsets between rotor hub and helicopter center of gravity

$=$ offset of the blade cross-sectional center of mass from the elastic axis

$=$ offset of the blade cross-sectional center of area from the elastic axis

$=$ longitudinal and vertical offsets between the tail rotor center from rotor hub center

$=$ spanwise location of center of microflap segment

$=$ aerodynamic state vector

$=$ output vector

$=$ airfoil angle of attack

$=$ rotor shaft angle

$=$ blade precone angle

$=$ control surface deflection

$=N / \mathrm{rev}$ cosine and sine components of the control surface deflection

$=$ lock number

$=$ rational approximant poles

$=$ helicopter advance ratio

$=$ rotor angular speed

$=$ oscillation frequency

$=$ nondimensional normal velocity distribution

= blade flap, lead-lag and torsional natural frequencies

$=$ azimuth angle

$=$ rotor solidity

$=$ built-in twist angle

\section{Introduction}

$\mathbf{T}$ HE microflap (shown in Fig. 1), sometimes called a deployable Gurney flap, has received considerable attention recently as a promising candidate for on-blade control in helicopter rotors as well as wind turbines. The Gurney flap is a small tab typically less than 5\% in chord and is attached normal to the airfoil at the trailing edge, as shown in Fig. 2. Depending on its size and location, the Gurney flap is capable of increasing the maximum lift coefficient of an airfoil by up to $30 \%$, based on experiments conducted at Reynolds numbers over $1 \times 10^{6}$ [1-4]. One of the earliest experimental studies on aerodynamics of a Gurney flap was conducted by Liebeck [1], who hypothesized that the Gurney flap caused the flow to turn around the trailing edge, resulting in the formation of two counter-rotating vortices behind it, as shown in Fig. 2. The turning of the flow shifts the trailing-edge stagnation point to the bottom edge of the Gurney flap, thus changing the Kutta condition and increasing the effective camber of the airfoil. The lift-enhancing capabilities of the Gurney flap have also been confirmed through several computational fluid dynamics (CFD) simulations [3 $3,5-7]$.

The microflap is deployable instead of being permanently fixed and thus is suitable for active control applications. Because of its small size, the microflap is suitable for high-bandwidth control with low actuation power requirements, minimal loss in structural stiffness of the wing, and lower wing warping when compared to the conventional control surfaces. The microflap has been studied for active control in several fixed-wing applications such as flutter suppression of high-aspect-ratio flexible wings [8], aeroelastic control of a blended wing-body configuration [9] , and wing trailingedge vortex alleviation [10-12]. It was shown that deployable microflaps can increase flutter speed of a highly flexible wing by up to $22 \%$ [8]. Another study has examined the use of microflaps for control of aeroelastic response at the wing tip of a flexible blended wing-body configuration [9]. Recent studies [10-12] also suggest that microflaps can be used for wake alleviation by inducing timevarying perturbations that excite vortex instability in the wake. The potential application of microflaps to active load control in wind turbine blades was also explored computationally and experimentally on representative turbine airfoil sections [7,13]. Substantial reduction in turbine blade root bending moment (reduction of peak bending moment ranging from 30 to $50 \%$ ) was observed in [14].

During the last two decades, active rotor control using individual blade control implemented through actively controlled partial-span trailingedge flaps (ACFs) has been shown to be effective for rotorcraft vibration and noise reduction [15-21] as well as rotor performance enhancement $[22,23]$. A computational study demonstrating simultaneous noise and vibration reduction in rotorcraft using the ACF system was presented in [19], where a fully coupled aeroelastic and aeroacoustic simulation capability was developed and incorporated into the comprehensive rotorcraft simulation code AVINOR (from "active vibration and noise reduction") [24]. A modified version of the helicopter aeroacoustic code WOPWOP [25] was used to calculate blade-vortex interaction (BVI) noise in descending flight at $\mu=0.15$. This unified aeroelastic/ aeroacoustic analysis code was also validated against experimental measurements, and good correlation was demonstrated. Up to $3-5 \mathrm{~dB}$ reduction in BVI noise was achieved in conjunction with $40 \%$ vibration reduction using single and dual ACF configurations. In addition to these computational studies, the effectiveness of the ACF system has also been demonstrated through wind-tunnel tests and flight tests $[18,20,21,26]$. Details about these tests are summarized in [15].

The advantages of the microflaps in terms of size and actuation power requirement when compared to the conventional ACFs make them an interesting alternative for on-blade rotor control. Several computational and experimental studies have considered microflaps for rotorcraft performance enhancement [27-29]. A relatively simple deployment schedule where the microflaps are deployed primarily on retreating side of the rotor disk was used, and the maximum thrust of the rotor was enhanced by $10 \%$ using microflaps with a height of $1 \%$

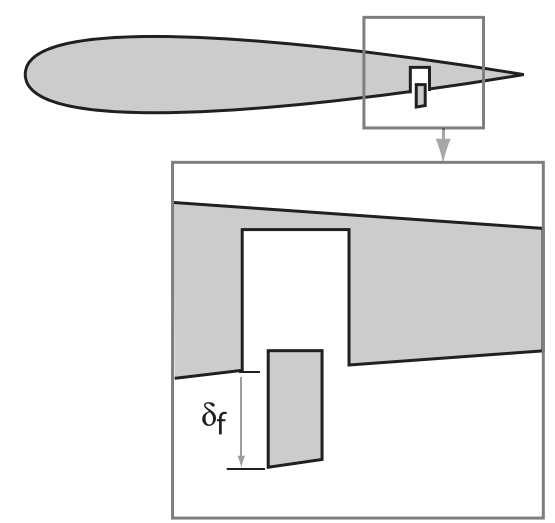

Fig. 1 Oscillating microflap cross section.

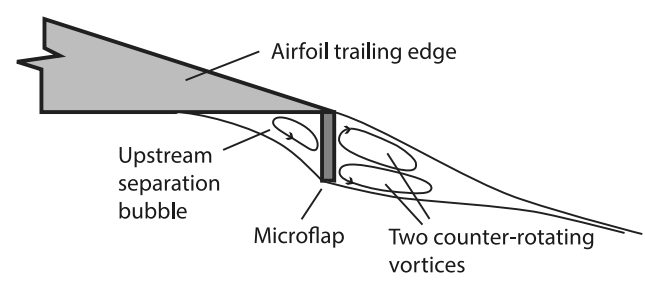

Fig. 2 Illustration of the Gurney flap. 
of chord distributed along the entire blade span. A Navier-Stokes flow solver coupled with a structural dynamics solver was employed in [30] to study the effectiveness of microflap for rotor vibration reduction. The oscillating microflap was simulated using a dynamic wall boundary condition. The microflap deflection magnitudes and phase angles were adjusted in the open-loop mode to identify the optimal input required for vibration reduction. More than $80 \%$ reduction in the vertical vibratory hub load was demonstrated using this approach. However, no closed-loop control studies were conducted. Recently, in [31], the authors of this paper studied three different microflap configurations using CFD. A sharp trailing-edge configuration, shown in Fig. 1 , was selected as a good compromise between the aerodynamic benefits and the ease of implementation. Furthermore, a reduced-order model for the unsteady microflap aerodynamics was developed based on CFD simulations, using the rational function approximation (RFA) approach. The resulting CFD + RFA model is a state-space, time-domain aerodynamic model that accounts for unsteadiness, compressibility, and time-varying freestream effects. The agreement between the reduced-order model and direct CFD calculations was found to be excellent for a wide range of flow conditions examined. This reduced-order model (ROM) was developed as a prerequisite for conducting closed-loop active vibration and noise reduction studies employing microflaps, which is the subject of this paper. The overall objective of this paper is to conduct a comprehensive computational evaluation of the potential of the microflap for active control in rotorcraft. The main emphasis here is on vibration and noise reduction, and a more limited study of performance enhancement using microflaps in curise condition is also conducted. The specific objectives of this paper are as follows.

1) Validate the aerodynamic and acoustic computations from the comprehensive rotorcraft simulation code against limited experimental data.

2) Explore the microflap's potential for active control of BVI noise at a low-speed descending flight condition where BVI effects are strong.

3) Examine the microflap's potential for active vibration reduction at various flight conditions.

4) For BVI conditions, investigate the effect of vibration reduction on noise, and vice versa.

5) Compare the vibration and noise reduction effectiveness of a microflap with that of a conventional plain trailing-edge flap.

6) Examine the potential of microflaps in cruise condition for rotor performance enhancement.

By achieving the objectives stated previously, the paper makes a valuable contribution to the exploration of microflap as an on-blade control device for helicopter vibration and noise reduction. The importance of this topic is enhanced due to the upcoming flight tests of an AugustaWestland AW139 helicopter with an active rotor incorporating microflaps [32].

\section{CFD Based ROM for an Airfoil Equipped with Microflap}

Modeling unsteady aerodynamics is a major challenge when conducting an aeroelastic analysis of a helicopter rotor blade equipped with microflaps. The strong nonlinear nature of viscous flow behind the microflap cannot be modeled using conventional potential flow methods. Therefore, the unsteady aerodynamic effects of the microflap need to be evaluated using a CFD-based approach. Although various CFD tools have been used to determine the aerodynamic characteristics of a Gurney flap or microflaps with reasonable accuracy, the computational costs of coupling CFD solvers directly with rotorcraft simulation codes are prohibitive when conducting parametric trend studies involving active control. Therefore, a ROM is essential for conducting studies aimed at determining the vibration and noise reduction capabilities of microflaps. The nonlinear CFD+RFA aerodynamic model developed in $[31,33]$ has been shown to be accurate, efficient, and suitable for combination with comprehensive rotorcraft codes. Furthermore, this model is suitable for representing both microflaps and conventional plain flaps. The ROM is obtained by using a compressible unsteady
Reynolds-averaged Navier-Stokes (RANS) CFD solver to generate frequency-domain aerodynamic response to generalized motions. Subsequently, the frequency domain loads are converted to the timedomain using the RFA approach.

The RFA approach has been used to generate two-dimensional time-domain unsteady aerodynamic loads for wing sections in both fixed-wing [34-37] and rotary-wing applications [38]. The original model developed in [38] was aimed at generating the unsteady crosssectional loads for an airfoil/trailing-edge flap combination, representing the cross section of the blade where a control surface is present. The model accounts for compressibility and variations in freestream velocity. In the original RFA model, the cross-sectional aerodynamic loads were obtained in the frequency domain using a doublet-lattice unsteady potential flow solver. Subsequently, a statespace formulation combined with the RFA approach was used to convert the loads to the time domain.

The new CFD based ROM also relies on the RFA approach, and therefore it is denoted as CFD+RFA model. Detailed descriptions of the model can be found in [31]. The essential features of the model are summarized in Fig. 3. The airfoil and plain flap combination can undergo four generalized motions $W_{0}, W_{1}, D_{0}$, and $D_{1}$, shown in the figure. For the airfoil and microflap combination, only three generalized motions $W_{0}, W_{1}$, and $D_{0}$, are used where $D_{0}$ is characterized by the microflap deflection. A CFD code is used to generate the frequency domain information for the airfoil/flap or airfoil/microflap configuration over a range of frequencies and flight conditions for which the ROM is expected to be used. Vector $\boldsymbol{h}$ in the figure represents the generalized motions corresponding to which cross-sectional frequency domain loads represented by the vector $f$ are generated. For the case of the plain flap shown in Fig. $\underline{3}$, the vector $f$ contains the lift coefficient $C_{l}$, the moment coefficient $C_{m}$, the hinge moment coefficient $C_{\mathrm{hm}}$, and the drag coefficient $C_{d}$. For the microflap, only three quantities are used because the hinge moment is not needed. The RFA approach is used to convert the frequency domain loads into the time domain using Laplace transforms. The final state-space representation relating the time-domain generalized motions $\boldsymbol{h}(t)$ to the generalized loads $\boldsymbol{f}(t)$ is shown in the block at the bottom of Fig. 3, where the vector $\boldsymbol{x}(t)$ represents the vector of augmented aerodynamic states. In the original version of the RFA approach, the matrices $\boldsymbol{R}, \boldsymbol{E}, \boldsymbol{C}_{0}$, and $\boldsymbol{C}_{1}$ associated with this approach were constant. To capture some of the nonlinear flow effects, in the new CFD+RFA model these matrices are defined as functions of the Mach number $M$, the effective angle of attack $\alpha$, and

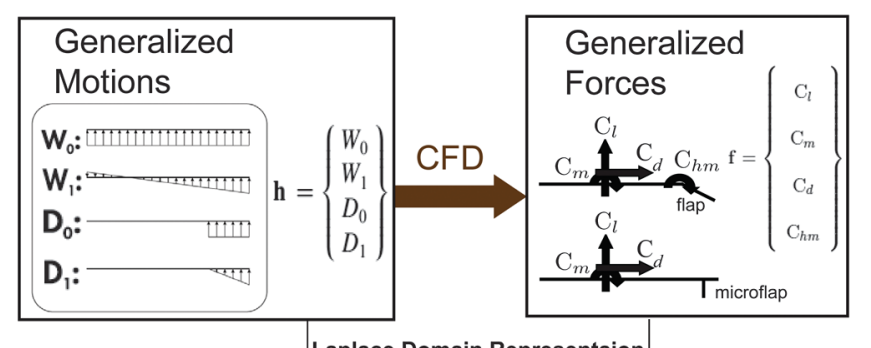

Laplace Domain Representaion

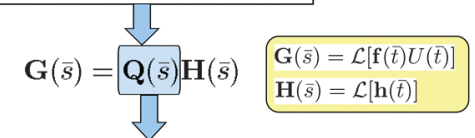

$$
\begin{aligned}
& \underbrace{\tilde{\mathbf{Q}}(\bar{s})=\mathbf{C}_{0}+\mathbf{C}_{1} \bar{s}+\sum_{n=1}^{n_{L}} \frac{\bar{s}}{\bar{s}+\gamma_{n}} \mathbf{C}_{n+1}}_{\begin{array}{c}
\text { RFA: } C_{i} \text { are evaluated using } \\
\text { least squares for best fit of aerodynamic data }
\end{array}} \\
& \text { 1. Inverse Laplace Transform } \\
& \begin{array}{c}
\dot{\mathbf{x}}(t)=\frac{U(t)}{b} \mathbf{R}\left(M, \alpha, \delta_{f}\right) \mathbf{x}(t)+\mathbf{E}\left(M, \alpha, \delta_{f}\right) \dot{\mathbf{h}}(t) \\
\mathbf{f}(t)=\frac{1}{U(t)}\left(\mathbf{C}_{0}\left(M, \alpha, \delta_{f}\right) \mathbf{h}(t)+\mathbf{C}_{1}\left(M, \alpha, \delta_{f}\right) \frac{b}{U(t)} \dot{\mathbf{h}}(t)+\mathbf{D x}(t)\right) \\
\text { State-space form with Model Scheduling }
\end{array}
\end{aligned}
$$

Fig. 3 Schematic description of the CFD based RFA model. 


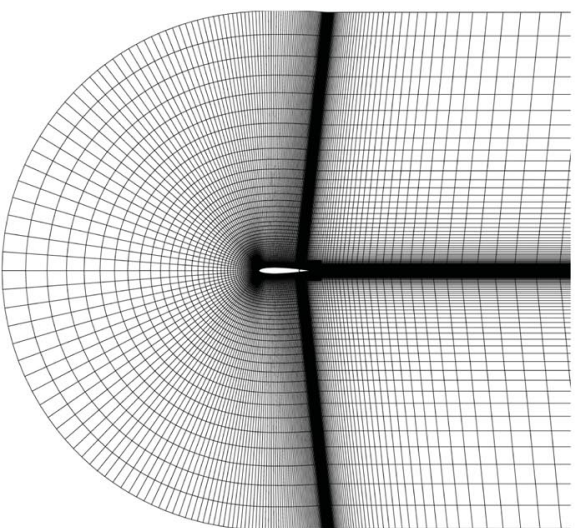

a) Grid overview

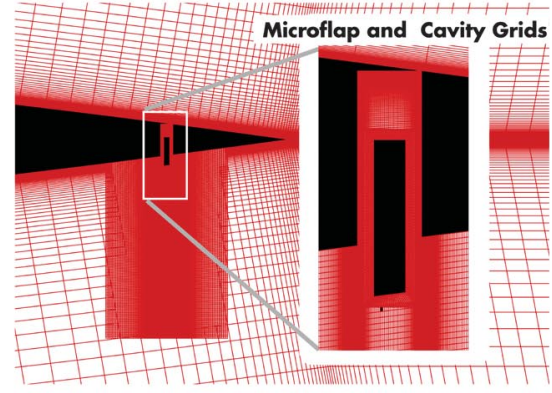

b) Close-up grid for microflap

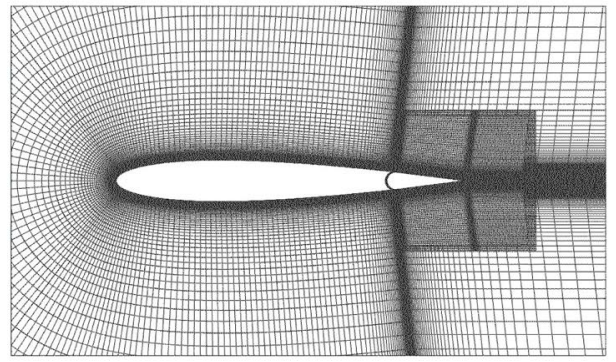

c) Close-up grid for plain flap

Fig. 4 Grids used for CFD simulations.

the flap deflection $\delta_{f}$. This modification of the original approach resembles gain scheduling used in the design of nonlinear control systems.

The CFD data required for constructing the ROM are obtained using the CFD++ code $[39,40]$, which is a modern commercially available code that solves the compressible unsteady RANS equations. It uses a unified grid methodology that can handle a variety of structured, unstructured, multiblock meshes, and cell types, including patched and overset grid features. Spatial discretization is based on a second-order multidimensional total variation diminishing scheme. For the temporal scheme, an implicit algorithm with dual time-stepping is employed to perform time-dependent flow simulations, with multigrid convergence acceleration. Of the various turbulence models available in CFD++, the Spalart-Allmaras model is used in the current study due to its simplicity and effectiveness. A fully turbulent boundary layer is assumed in all the simulations.

The sharp trailing-edge configuration shown in Fig. 1 is used in the current study. The CFD grids employed are shown in Fig. 4b; grids for a $20 \%$ plain flap are also shown in Fig. 4c. The overall computational domain is shown in Fig. 4a, which contains approximately 90,000 grid points. The CFD grids for the various microflap or plain flap configurations are generated using the overset approach, which is a convenient method for modeling complex geometries and moving components with large relative motions. The grids are clustered at the airfoil wall boundaries such that the dimensionless distance $y^{+}$of the first grid point off the wall is less than 1 , and the equations are solved directly to the walls without assuming wall functions.

To generate a ROM that represents the entire range of flow conditions encountered by the blades at various advance ratios, CFD simulations are conducted for Mach numbers ranging from 0.05 to 0.9 and angles of attack ranging from 0 to $15 \mathrm{deg}$. All the simulations are carried out using the NACA 0012 airfoil at Reynolds number $2.1 \times 10^{6}$. The NACA 0012 airfoil was chosen because experimental aerodynamic load data based on it are easily available in the literature. This experimental data were used to validate the CFD data in [31]. At each flow condition defined by the freestream Mach number and the airfoil mean angle of attack, simulations are performed to generate frequency-domain data corresponding to the various generalized motions for reduced frequency values ranging from 0.02 to 0.2 with an increment of 0.02 . Note that the $5 / \mathrm{rev}$ frequency at $0.75 R$ span location on the rotor blade of a hovering Messerschmitt-BölkowBlohm (MBB) BO-105 rotor configuration corresponds to a reduced frequency of 0.18 . Frequency-domain data obtained through CFD simulations at the prescribed flow conditions are used to generate the coefficients $C_{0}, C_{1}, \ldots, C_{n}$ in the CFD+RFA reduced-order model. Subsequently, a "shape-preserving" piecewise cubic Hermite polynomial interpolation scheme [41-43] is used to evaluate the coefficients at intermediate flow conditions. The CFD+RFA model was extensively verified in [31] for a wide range of flow conditions and unsteady microflap/plain flap deflections by comparing the ROM predictions to direct CFD simulations. The CFD grids and simulations were validated by comparing the results to existing experimental data for a stationary Gurney flap [31].

\section{Description of the Rotorcraft Aeroelastic Analysis Code}

Active vibration and noise reduction studies with the microflap and the plain flap are conducted using a comprehensive rotorcraft aeroelastic analysis code AVINOR, which has been extensively validated in previous studies $[19,24,44]$. The CFD+RFA model described earlier is incorporated into AVINOR and is employed for modeling the two-dimensional aerodynamic effects of the microflaps and plain trailing-edge flaps. The principal ingredients of the AVINOR code are concisely summarized next.

\section{A. Structural Dynamic Model}

The structural dynamic model used in this study consists of a fourbladed hingeless rotor, with fully coupled flap-lag-torsional dynamics for each blade. The structural dynamic model is geometrically nonlinear due to moderate blade deflections. The structural equations of motion are discretized using the global Galerkin method, based upon the free vibration modes of the rotating blade. The dynamics of the blade are represented by three flap, two lead-lag, and two torsional modes. Each of the free vibration modes of the rotating blade was obtained using the corresponding first nine exact nonrotating modes of a uniform cantilevered beam. That is, the torsional modes for the 
rotating blade are calculated using the first nine torsional nonrotating modes of a uniform cantilevered beam and similarly for the flap and lead-lag motions. Thus, a total of 27 nonrotating free vibration modes have been considered. The effect of control surfaces such as the trailing-edge plain flap or the microflap on the structural properties of the blade were neglected. Thus, the control surfaces influence the blade behavior only through their effect on the aerodynamic and inertial loads.

\section{B. Aerodynamic Model}

The blade/flap or blade/microflap sectional aerodynamic loads for attached flow are calculated using the CFD+RFA model described earlier. This model provides cross-sectional unsteady lift, moment, and drag for both plain flap and microflap configurations. The RFA model is linked to a free-wake model, described in [19], that yields a spanwise and azimuthally varying inflow distribution. For separated flow regime, the aerodynamic loads are calculated using the ONERA-The French Aerospace Lab dynamic-stall model [19]. In this study, the microflaps are assumed to be in sections without dynamic stall. This is a valid assumption for the advance ratios considered. No corrections have been made to the ONERA model to account for microflaps.

\section{Coupled Aeroelastic Response/Trim Solution}

The combined structural and aerodynamic equations are represented by a system of coupled ordinary differential equations with periodic coefficients in state-variable form. The trim employed is a propulsive trim procedure where three force equations (longitudinal, lateral, and vertical) and three moment equations (roll, pitch, and yaw) corresponding to a helicopter in free flight are enforced. A simplified tail rotor model, based on uniform inflow and blade-element theory, is used. The six trim variables are the rotor shaft angle $\alpha_{R}$, the collective pitch $\theta_{0}$, the cyclic pitch $\theta_{1 s}$ and $\theta_{1 c}$, the lateral roll angle $\phi_{R}$, and the tail rotor constant pitch $\theta_{0 t}$. The coupled trim/aeroelastic equations are solved in time using the ordinary differential equations solver DDEABM, which is a predictor-corrector-based Adams-Bashforth differential system solver.

\section{Acoustic Model}

The acoustic calculations are based on a modified version of the WOPWOP code, where helicopter noise is obtained from the Ffowcs Williams-Hawkings equation with the quadrupole term neglected [25]. The WOPWOP code was modified to account for the fully flexible blade model used in AVINOR in $[\underline{19}, \underline{45}]$. However, in these studies, the chordwise pressure distribution on the surface of the blade, which is an input required for the acoustic computations, was obtained using an extended RFA approach. The extended RFA approach used frequency-domain pressure data obtained from the doublet-lattice flow solver as described in detail in [45]. Generating the extended RFA models using CFD-based pressure distribution data is computationally expensive. As an alternative, the bladepressure distributions in this study are obtained using an approximate velocity superposition method [46]. This method is based on the potential flow theory wherein the pressure distribution on the surface of the airfoil is related to the local velocity distribution as

$$
C_{p}=\left(\frac{v}{V} \pm \frac{\Delta v}{V} \pm \frac{\Delta v_{a}}{V}\right)^{2}
$$

where the velocity ratios $v / V, \Delta v / V$, and $\Delta v_{a} / V$ are contributions to the velocity distribution due to airfoil thickness, camber, and angle of attack, respectively. The signs in Eq. (1) are positive for the upper surface and negative for the lower surface of the airfoil. For the symmetric NACA 0012 airfoil used in the study, $\Delta v / V=0$, and the values of the other two components corresponding to the total lift coefficient are determined from a table lookup provided in [46]. In this study, the effect of microflap is accounted for in the total lift coefficient. This approach represents an acceptable approximation because the lift coefficients, from which the pressure distributions are obtained, are based on the CFD+RFA model that accounts for compressibility, viscosity, and unsteady effects.

\section{Higher Harmonic Control Algorithm}

The active control studies in this paper are based on the higher harmonic control (HHC) algorithm, which has been used extensively for active control of vibration and noise in rotorcraft $[15,19,47]$. The algorithm is based on the assumption that the helicopter can be represented by a linear model relating the output of interest $z$ to the control input $\boldsymbol{u}$. The measurement of the plant output and update of the control input are performed at specific times $t_{k}=k \tau$, where $\tau$ is the time interval between updates during which the plant output reaches a steady state. In actual implementation of the algorithm, this time interval may be one or more revolutions. A schematic of the HHC architecture implemented on a helicopter is shown in Fig. 5 . The output vector at the $k$ th time step is given by

$$
z_{k}=\boldsymbol{T} \boldsymbol{u}_{k}+\boldsymbol{W} \boldsymbol{w}
$$

where the sensitivity matrix $\boldsymbol{T}$ represents a linear approximation of the helicopter response to the control and is given by

$$
\boldsymbol{T}=\frac{\partial z}{\partial \boldsymbol{u}}
$$

At the initial condition, $k=0$,

$$
z_{0}=\boldsymbol{T} \boldsymbol{u}_{0}+\boldsymbol{W} \boldsymbol{w}
$$

Subtracting Eq. (4) from Eq. (2) to eliminate the unknown $w$ yields

$$
z_{k}=z_{0}+\boldsymbol{T}\left(\boldsymbol{u}_{k}-\boldsymbol{u}_{0}\right)
$$

The controller is based on the minimization of a general quadratic cost function

$$
J\left(z_{k}, \boldsymbol{u}_{k}\right)=z_{k}^{\mathrm{T}} \boldsymbol{Q}_{z} z_{k}+2 z_{k}^{\mathrm{T}} \boldsymbol{S} \boldsymbol{u}_{k}+\boldsymbol{u}_{k}^{\mathrm{T}} \boldsymbol{R} \boldsymbol{u}_{k}
$$

However, in most applications, the cross-weighting term in Eq. (6) is neglected; thus, the cost function reduces to

$$
J\left(z_{k}, \boldsymbol{u}_{k}\right)=z_{k}^{\mathrm{T}} \boldsymbol{Q}_{z} z_{k}+\boldsymbol{u}_{k}^{\mathrm{T}} \boldsymbol{R} \boldsymbol{u}_{k}
$$

The optimal control input is determined from the requirement

$$
\frac{\partial J\left(z_{k}, \boldsymbol{u}_{k}\right)}{\partial \boldsymbol{u}_{k}}=0
$$

which yields the optimal control law $\boldsymbol{u}_{k, \text { opt }}$, given by

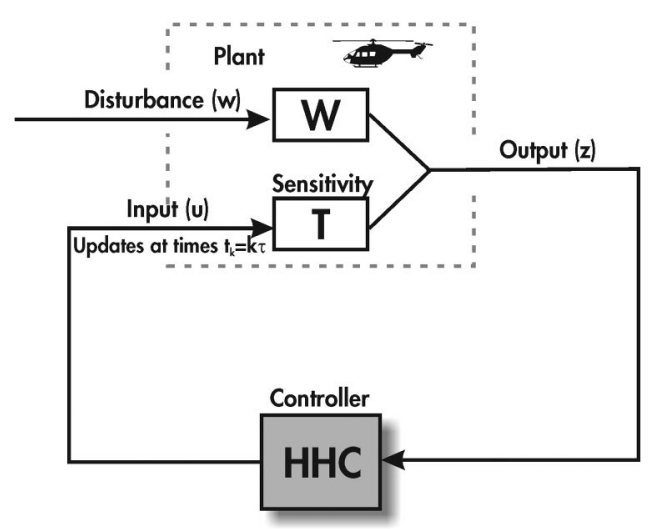

Fig. 5 Higher harmonic control architecture. 


$$
\boldsymbol{u}_{k, \mathrm{opt}}=-\left(\boldsymbol{T}^{\mathrm{T}} \boldsymbol{Q}_{z} \boldsymbol{T}+\boldsymbol{R}\right)^{-1}\left(\boldsymbol{T}^{\mathrm{T}} \boldsymbol{Q}_{z}\right)\left(z_{0}-\boldsymbol{T} \boldsymbol{u}_{0}\right)
$$

Combining Eqs. (ㄷ) $)$ (7), and (9)), the minimum cost is

$$
J\left(z_{k}, \boldsymbol{u}_{k, \text { opt }}\right)=\left(z_{0}-\boldsymbol{T} \boldsymbol{u}_{0}\right)^{\mathrm{T}}\left[\boldsymbol{Q}_{z}-\left(\boldsymbol{Q}_{z} \boldsymbol{T}\right) \boldsymbol{D}^{-1}\left(\boldsymbol{T}^{\mathrm{T}} \boldsymbol{Q}_{z}\right)\right]\left(z_{0}-\boldsymbol{T} \boldsymbol{u}_{0}\right)
$$

where

$$
\boldsymbol{D}=\boldsymbol{T}^{\mathrm{T}} \boldsymbol{Q}_{z} \boldsymbol{T}+\boldsymbol{R}
$$

This is a classical version of the HHC algorithm that yields an explicit relation for the optimal control input. Another version of the HHC algorithm where the sensitivity matrix $\boldsymbol{T}$ is updated using leastsquares methods after every control update is known as the adaptive or recursive HHC [47]. To describe the adaptive HHC algorithm, relative output and input vectors are defined, $\Delta z_{k}$ with length $2 p$ and $\Delta \boldsymbol{u}_{k}$ with length $2 m$ as

$$
\Delta \boldsymbol{z}_{k}=\boldsymbol{z}_{k}-\boldsymbol{z}_{k-1}, \quad \Delta \boldsymbol{u}_{k}=\boldsymbol{u}_{k}-\boldsymbol{u}_{k-1}
$$

and $\Delta \boldsymbol{Z}_{k}$ of size $2 p \times k$ and $\Delta \boldsymbol{U}_{k}$ of size $2 m \times k$ as

$$
\Delta \boldsymbol{Z}_{k}=\left[\begin{array}{lll}
\Delta \boldsymbol{z}_{1} & \cdots & \Delta \boldsymbol{z}_{k}
\end{array}\right], \quad \Delta \boldsymbol{U}_{k}=\left[\begin{array}{lll}
\Delta \boldsymbol{u}_{1} & \cdots & \Delta \boldsymbol{u}_{k}
\end{array}\right]
$$

The relation between the successive updates of vibration levels $z_{k}$ is

$$
\boldsymbol{z}_{k}=\boldsymbol{z}_{k-1}+\boldsymbol{T}\left(\boldsymbol{u}_{k}-\boldsymbol{u}_{k-1}\right)
$$

This can be represented in another form:

$$
\Delta \boldsymbol{z}_{k}=\boldsymbol{T} \Delta \boldsymbol{u}_{k}
$$

Hence, it follows from Eqs. (13) and (15) that

$$
\Delta \boldsymbol{Z}_{k}=\boldsymbol{T} \Delta \boldsymbol{U}_{k}
$$

Assuming that $\Delta \boldsymbol{U}_{k} \Delta \boldsymbol{U}_{k}^{\mathrm{T}}$ is nonsingular, one can define

$$
\boldsymbol{P}_{k}=\left(\Delta \boldsymbol{U}_{k} \Delta \boldsymbol{U}_{k}^{\mathrm{T}}\right)^{-1}
$$

and from Eq. (16), the least-squares estimate $\hat{\boldsymbol{T}}_{\mathrm{LS}_{k}}$ of $\boldsymbol{T}$ is given by

$$
\hat{\boldsymbol{T}}_{\mathrm{LS}_{k}}=\Delta \boldsymbol{Z}_{k} \Delta \boldsymbol{U}_{k}^{\mathrm{T}} \boldsymbol{P}_{k}
$$

The recursive least-squares method is used to iteratively update $\hat{\boldsymbol{T}}_{\mathrm{LS}_{k}}$ based on the past and current values of $\Delta \boldsymbol{z}_{k}$ and $\Delta \boldsymbol{u}_{k}$. The updated estimate $\hat{\boldsymbol{T}}_{\mathrm{LS}_{k}}$ is used at each control update step to calculate the optimal control input $\boldsymbol{u}_{k, \text { opt }}$ as follows:

$$
\boldsymbol{u}_{k, \mathrm{opt}}=-\left(\hat{\boldsymbol{T}}_{\mathrm{LS}_{k}}^{\mathrm{T}} \boldsymbol{Q}_{z} \hat{\boldsymbol{T}}_{\mathrm{LS}_{k}}+\boldsymbol{R}\right)^{-1}\left(\hat{\boldsymbol{T}}_{\mathrm{LS}_{k}}^{\mathrm{T}} \boldsymbol{Q}_{z}\right)\left(z_{0}-\hat{\boldsymbol{T}}_{\mathrm{LS}_{k}} \boldsymbol{u}_{0}\right)
$$

The adaptive HHC algorithm has been shown to perform better than the classical HHC when the model nonlinearities are significant, and the sensitivity matrix $\boldsymbol{T}$ is a poor approximation of the model [47]. Thus, the adaptive HHC algorithm is used for all the active control results generated in this paper.

For a four-bladed rotor, the control input $\boldsymbol{u}_{k}$ is a combination of $2 / \mathrm{rev}, 3 / \mathrm{rev}, 4 / \mathrm{rev}$, and 5/rev harmonic amplitudes of the control surface deflection:

$$
\boldsymbol{u}_{k}=\left[\delta_{2 c}, \delta_{2 s}, \ldots, \delta_{5 c}, \delta_{5 s}\right]^{T}
$$

The term "control surface" refers to both the microflap and the conventional plain trailing-edge flap. The total control surface deflection is given by

$$
\delta\left(\psi, \boldsymbol{u}_{k}\right)=\sum_{N=2}^{5}\left[\delta_{N c} \cos (N \psi)+\delta_{N s} \sin (N \psi)\right]
$$

where the quantities $\delta_{N c}$ and $\delta_{N s}$ correspond to the cosine and sine components of the $N /$ rev control input harmonic. When multiple control surfaces are used, the control surface deflections are given by

$$
\delta_{i}\left(\psi, \boldsymbol{u}_{k}\right)=\sum_{N=2}^{5}\left[\delta_{N c i} \cos (N \psi)+\delta_{N s i} \sin (N \psi)\right]
$$

where $i=1, \ldots, N_{\delta}$, and $N_{\delta}$ is the total number of control surfaces. The control vector $\boldsymbol{u}_{k}$ is then given by

$$
\boldsymbol{u}_{k}=\left[\delta_{2 c 1}, \delta_{2 s 1}, \ldots, \delta_{5 c 1}, \delta_{5 s 1}, \ldots, \delta_{2 c N_{\delta}}, \delta_{2 s N_{\delta}}, \ldots, \delta_{5 c N_{\delta}}, \delta_{5 s N_{\delta}}\right]^{T}
$$

For vibration reduction studies, the output vector $z_{k}$ consists of $4 /$ rev vibratory hub shears and moments:

$$
\boldsymbol{z}_{\mathrm{vr}}=\left[\begin{array}{c}
F_{H X 4} \\
F_{H Y 4} \\
F_{H Z 4} \\
M_{H X 4} \\
M_{H Y 4} \\
M_{H Z 4}
\end{array}\right]
$$

The weighting matrix $\boldsymbol{Q}_{z}$ in the cost function [see Eq. (7)] is a diagonal matrix, and for vibration control, it is described by six weights corresponding to the three nondimensional vibratory hub shears and the three nondimensional vibratory hub moments. Based on previous studies [19], the weights for the hub shears were assumed to be identical, and a similar assumption was used for the weights of the hub moments. The weighting matrix used in this study for vibration reduction, $\boldsymbol{Q}_{z \mathrm{vr}}$, is

$$
\boldsymbol{Q}_{z \mathrm{vr}}=\left[\begin{array}{cccccc}
1 & 0 & 0 & 0 & 0 & 0 \\
0 & 1 & 0 & 0 & 0 & 0 \\
0 & 0 & 1 & 0 & 0 & 0 \\
0 & 0 & 0 & 10 & 0 & 0 \\
0 & 0 & 0 & 0 & 10 & 0 \\
0 & 0 & 0 & 0 & 0 & 10
\end{array}\right]
$$

The hub moments are an order of magnitude smaller compared to the hub shears; therefore, the weights on the moments are 10 times those on the hub shears. For BVI noise reduction (NR) studies, the output vector consists of the 6th-17th blade-passage frequency harmonic components of BVI noise (the most significant part of BVI noise), as measured by a microphone installed at a suitable

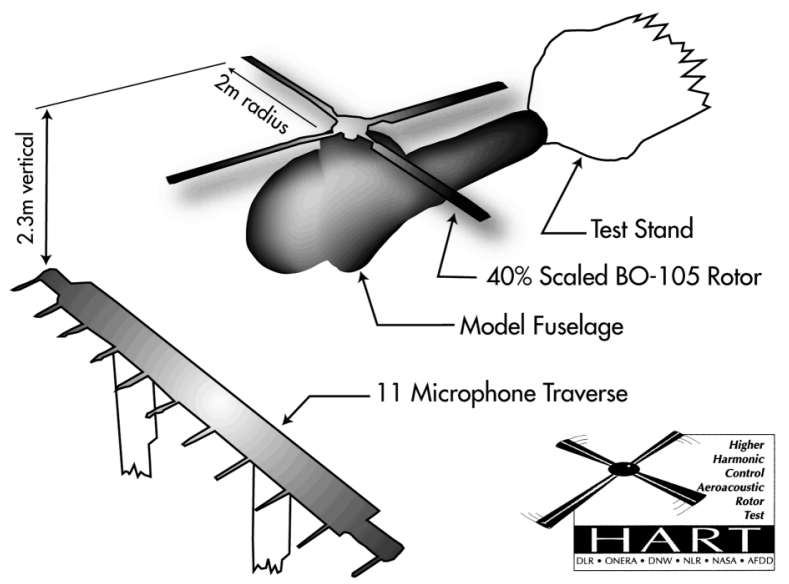

Fig. 6 HART test setup. 
location. In this paper, the microphone is located on the rear of the right skid, and

$$
\boldsymbol{z}_{\mathrm{nr}}=\left[\begin{array}{c}
N_{H 06} \\
N_{H 07} \\
N_{H 08} \\
\vdots \\
N_{H 17}
\end{array}\right]
$$

The noise control law is identical to the control law used for vibration reduction. The weighting matrix used in this study for NR is an identity matrix:

$$
\boldsymbol{Q}_{z \mathrm{nr}}=\left[\begin{array}{ccccccc}
1 & 0 & 0 & 0 & \ldots & \ldots & 0 \\
0 & 1 & 0 & 0 & \ldots & \ldots & 0 \\
0 & 0 & 1 & 0 & \ldots & \ldots & 0 \\
& & & \ddots & & & \\
0 & \ldots & \ldots & 0 & 1 & 0 & 0 \\
0 & \ldots & \ldots & 0 & 0 & 1 & 0 \\
0 & \ldots & \ldots & 0 & 0 & 0 & 1
\end{array}\right]
$$

Note that all the components of the BVI noise are weighted equally.

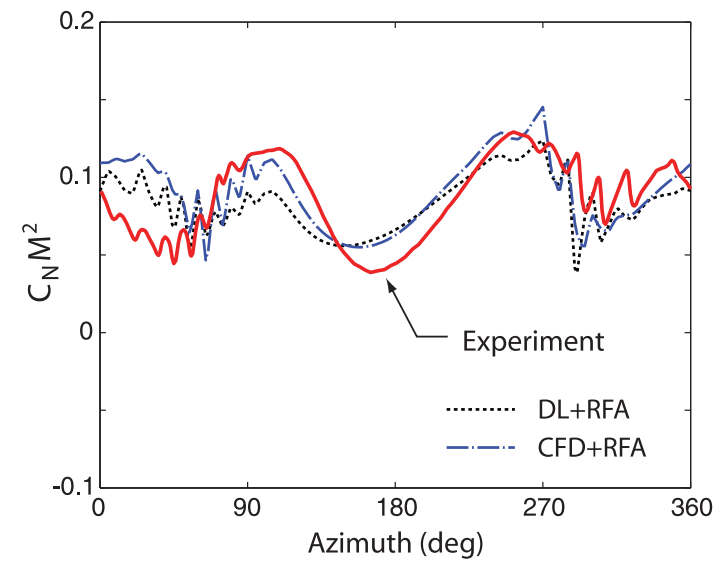

Fig. 7 Validation of the aerodynamic load computations with the HART experimental data at $r / R=0.87$
Table 1 Rotor parameters

\begin{tabular}{|c|c|}
\hline Parameter & Value \\
\hline \multicolumn{2}{|c|}{ Dimensional main rotor data } \\
\hline$R$ & $4.91 \mathrm{~m}$ \\
\hline$M_{b}$ & $27.35 \mathrm{~kg}$ \\
\hline$\Omega$ & $425 \mathrm{rpm}$ \\
\hline \multicolumn{2}{|c|}{ Nondimensional main rotor data } \\
\hline$N_{b}$ & 4 \\
\hline$L_{b}$ & 1.0 \\
\hline$X_{A}$ & 0 \\
\hline$X_{I b}$ & 0 \\
\hline$I_{M B 2}$ & 0 \\
\hline $\mathrm{EI}_{\eta \eta}$ & 0.0302 \\
\hline $\mathrm{GJ}_{b}^{\prime \prime}$ & 0.0015 \\
\hline$\omega_{F 2}$ & 3.404 \\
\hline$\omega_{L 1}$ & 0.732 \\
\hline$\omega_{T 1}$ & 3.170 \\
\hline$\gamma$ & 5.5 \\
\hline$\theta_{t w}$ & $-8 \mathrm{deg}$ \\
\hline$c$ & $0.05498 R$ \\
\hline$e$ & 0 \\
\hline$\beta_{p}$ & $2.5 \mathrm{deg}$ \\
\hline$X_{U b}$ & 0 \\
\hline$I_{M B 3}$ & 0.0004 \\
\hline $\mathrm{EI}_{\zeta \zeta}$ & 0.0105 \\
\hline$\omega_{F 1}$ & 1.124 \\
\hline$\omega_{F 3}$ & 7.606 \\
\hline$\omega_{L 2}$ & 4.458 \\
\hline$\omega_{T 2}$ & 9.079 \\
\hline$\Sigma$ & 0.07 \\
\hline \multicolumn{2}{|c|}{ Nondimensional tail rotor data } \\
\hline$X_{t}$ & 1.20 \\
\hline$Z_{t}$ & 0 \\
\hline \multicolumn{2}{|c|}{ Helicopter data } \\
\hline$C_{W}$ & 0.005 \\
\hline$X_{\mathrm{FA}}^{n}$ & 0.0 \\
\hline$X_{\mathrm{FC}}$ & 0.0 \\
\hline$f C_{\mathrm{df}}$ & 0.031 \\
\hline$Z_{\mathrm{FA}}$ & 0.3 \\
\hline$Z_{\mathrm{FC}}$ & 0.3 \\
\hline \multicolumn{2}{|c|}{ Feedback microphone location } \\
\hline$X_{\mathrm{Mi}}$ & 0.10 \\
\hline$Z_{\mathrm{Mi}}$ & -0.60 \\
\hline$Y_{\mathrm{Mi}}$ & 0.32 \\
\hline
\end{tabular}
used for the computations
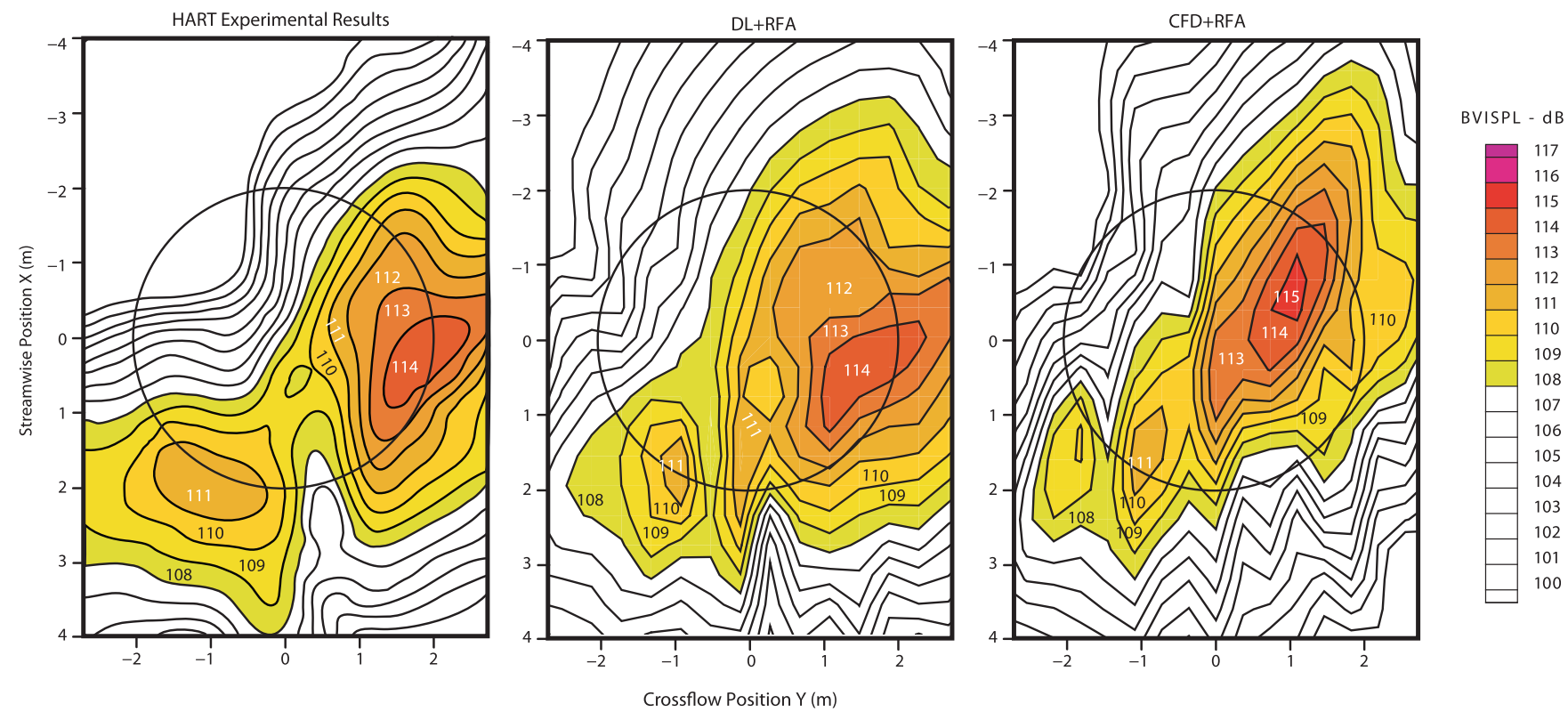

Fig. 8 Validation of the acoustic computations with the HART experimental data. 
Using active control for rotor performance enhancement requires a different objective, namely the rotor power, given by

$$
z_{\mathrm{pr}}=\left[P_{R}\right]
$$

where $P_{R}$ denotes the average rotor shaft power. The average rotor power is defined as the power required to drive the rotor at a constant angular velocity $\Omega$ averaged over one revolution:

$$
P_{R}=\frac{\Omega}{2 \pi} \int_{0}^{2 \pi}-M_{H z 1}(\psi) \mathrm{d} \psi
$$

where $M_{H z 1}$ is the total yawing moment about the hub and includes the effect of unsteadiness, compressibility, dynamic stall, and the additional drag due to microflap deflection. To impose saturation limits on the flap or microflap deflection, an algorithm known as autoweighting, developed in [48], is used. In this approach, the control weighting matrix, $\boldsymbol{R}$ in Eq. (7), is updated so as to restrict the control surface deflection.
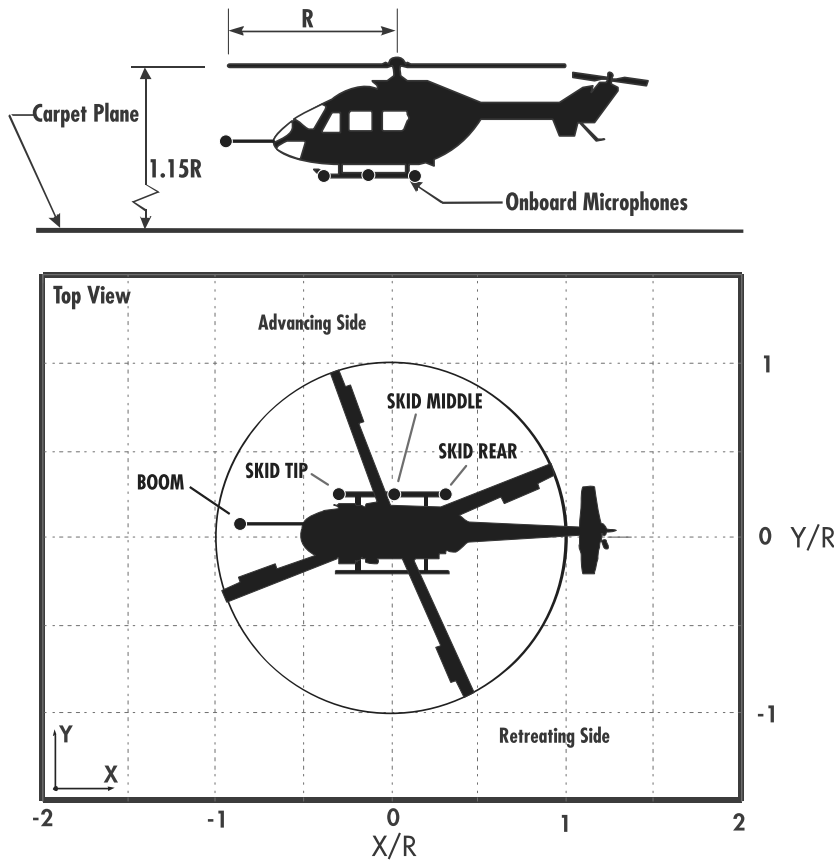

Fig. 9 Carpet plane and microphone locations on and around the helicopter for noise measurements.

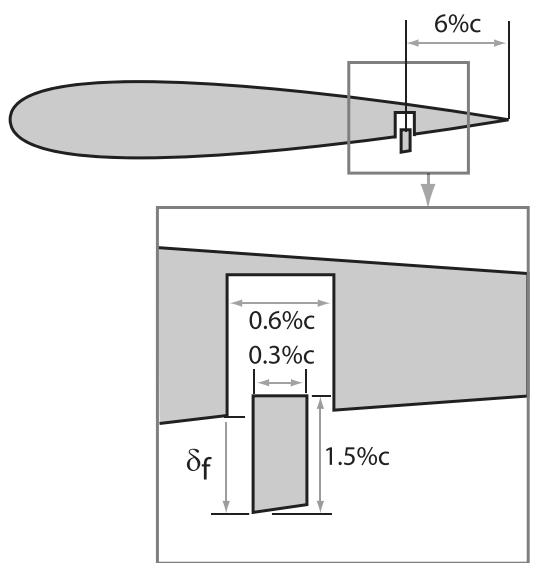

Fig. 10 Oscillating microflap in a cavity depicting the sharp trailingedge configuration.

\section{Validation Studies}

In this section, the combined aeroelastic-aeroacoustic simulation code AVINOR employing the CFD-based ROM is validated against the experimental data obtained in the Higher Harmonic Control Aeroacoustic Rotor Test (HART) program [49] conducted in the German-Dutch Wind Tunnel. The HART rotor is a $40 \%$ dynamically and Mach-scaled model of a four-bladed hingeless MBB BO-105 main rotor, with -8 deg linear twist and standard rectangular planform. The test setup is depicted in Fig. $\underline{6}$. One of the blades was

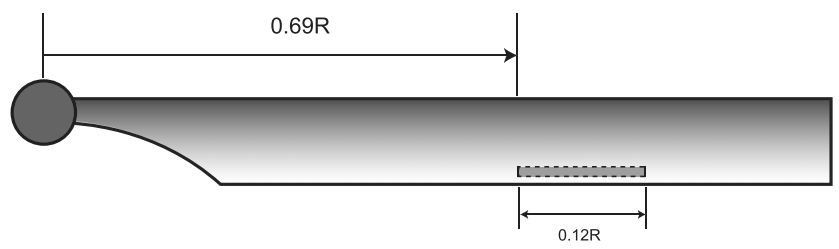

a) Single microflap

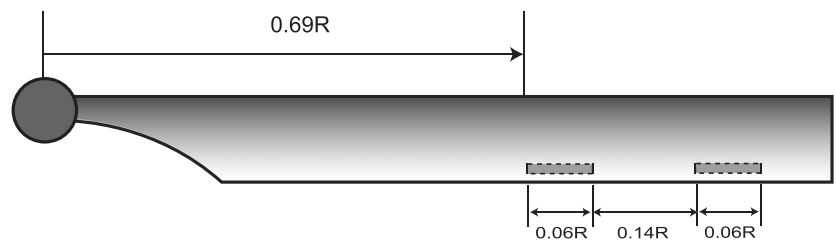

b) Dual microflap

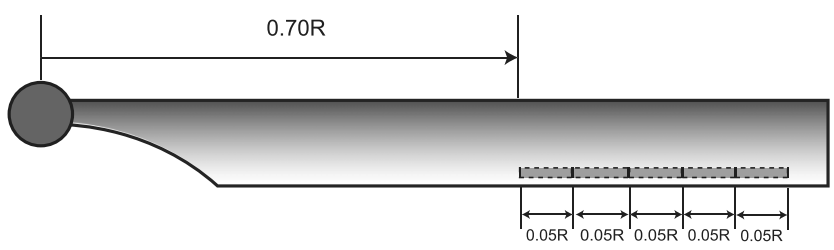

c) Five microflaps

Fig. 11 Various spanwise configurations of the microflap on the rotor blade.

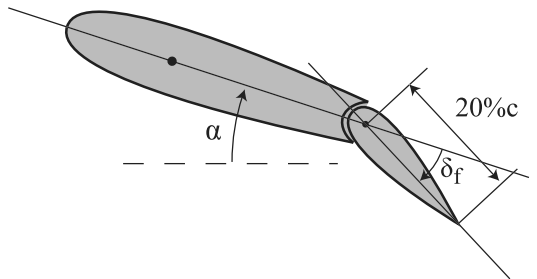

Fig. $1220 \% c$ conventional plain flap configuration.

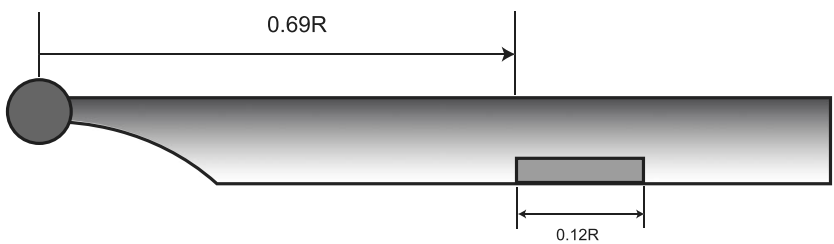

a) Single plain flap

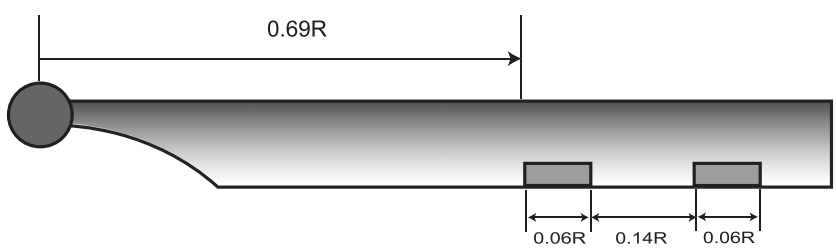

b) Dual plain flap

Fig. 13 Single and dual spanwise configurations of the $20 \% c$ plain flap on the rotor blade. 
equipped with pressure transducers so that the blade airloads could be measured at various radial locations. Microphone arrays were placed on a traverse stand at a distance of 1.15 rotor radii underneath the rotor hub and moved across the horizontal plane to measure the rotor noise at various locations. The rotor was trimmed for a given advance ratio $\mu$, thrust coefficient $C_{T}$, and rotor shaft angle $\alpha_{R}$, using collective and $1 /$ rev cyclic pitch inputs. The comparisons presented in this section correspond the baseline condition (i.e., no active control) in the HART experiments. The baseline flight condition corresponds to a typical BVI flight condition, with $\mu=0.15, C_{T}=0.044$, and $\alpha_{R}=5.3 \mathrm{deg}$.

The aerodynamic loads measured at a location $r / R=0.87$ along the span of the blade obtained from the simulation and those measured in the HART study are compared in Fig. 7. Aerodynamic loads obtained using the original doublet-lattice-based and the new CFD-based aerodynamic models are shown in Fig. 7. The vertical axis in Fig. 7 represents a nondimensional quantity equal to the product of the normal force coefficient and the square of the local Mach number. Both simulations capture the BVI events represented by the high-frequency fluctuations in the aerodynamic loads, also found in the experimental data. Note that the prediction from the CFD + RFA model captures the overall shape of the aerodynamic load time histories better than the Doublet Lattice (DL)-based aerodynamic model.

As indicated earlier, the acoustic noise levels were measured by traversing a microphone array positioned $1.15 R$ below the rotor, as shown in Fig. 6 . From these data, time-averaged noise levels in decibels were computed on a "carpet plane" located $1.15 R$ below the rotor hub and parallel to the hub plane. Comparison of the noise levels on the carpet plane obtained from the simulations and the HART experiments are shown in Fig. 8. Noise predicted using the original DL+RFA aerodynamic model is reproduced from [45]. The magnitudes of the BVI noise levels are predicted reasonably well by both the DL+RFA and CFD+RFA aerodynamic models. However, the DL+RFA model produced better agreement with the experimental data than the CFD+RFA model in the location of the high BVI noise region on the advancing side. Note that the unsteady chordwise pressure distribution is calculated differently for the two models, as noted in Sec. III.D. The discrepancies observed in Fig. $\underline{8}$ can be attributed to the different pressure calculations.

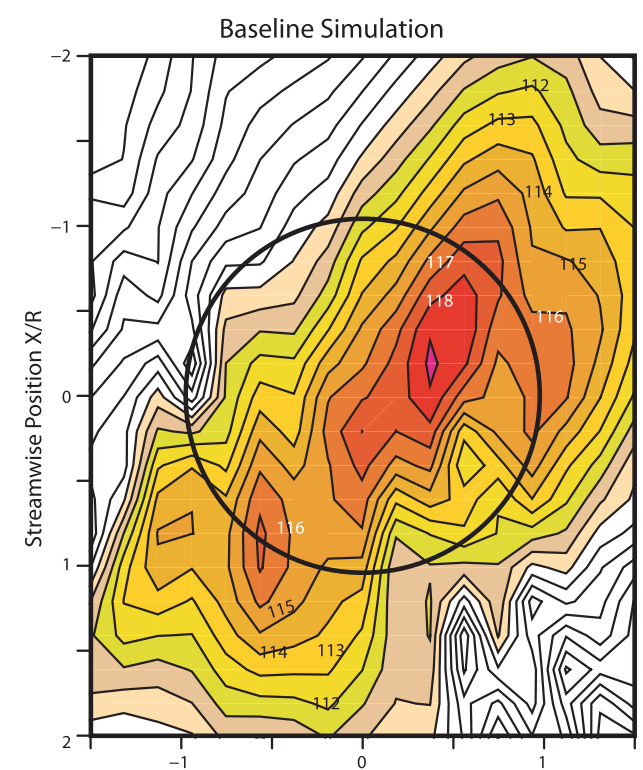

a)

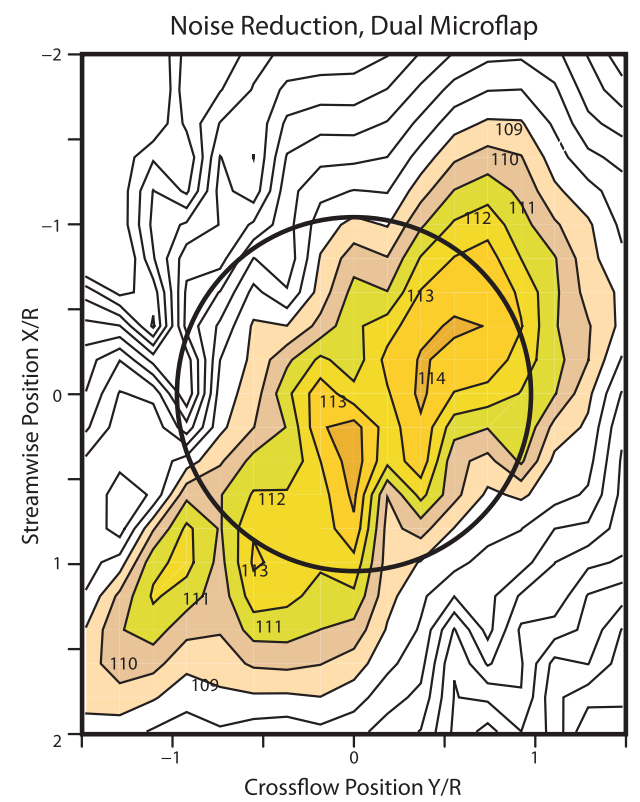

c)

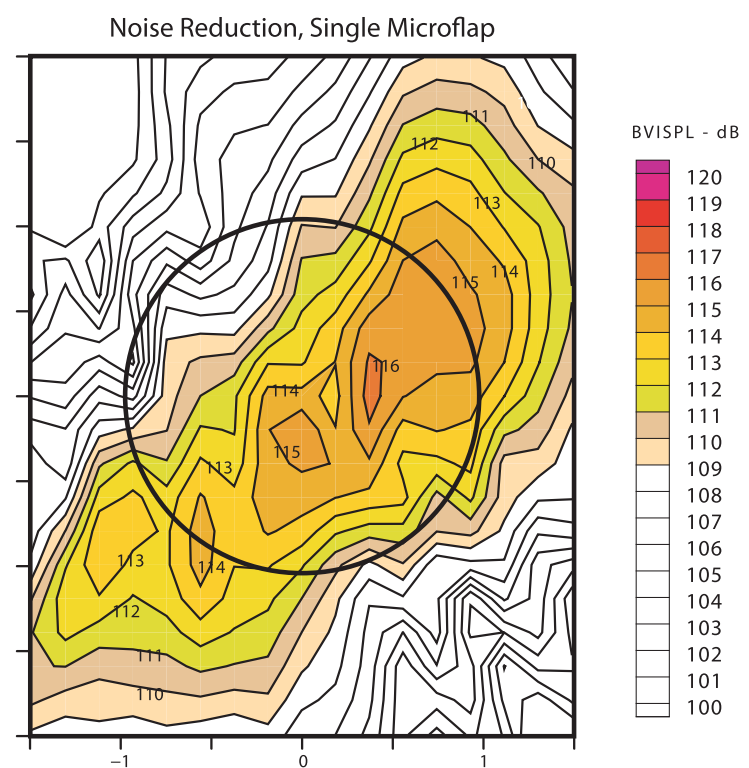

b)

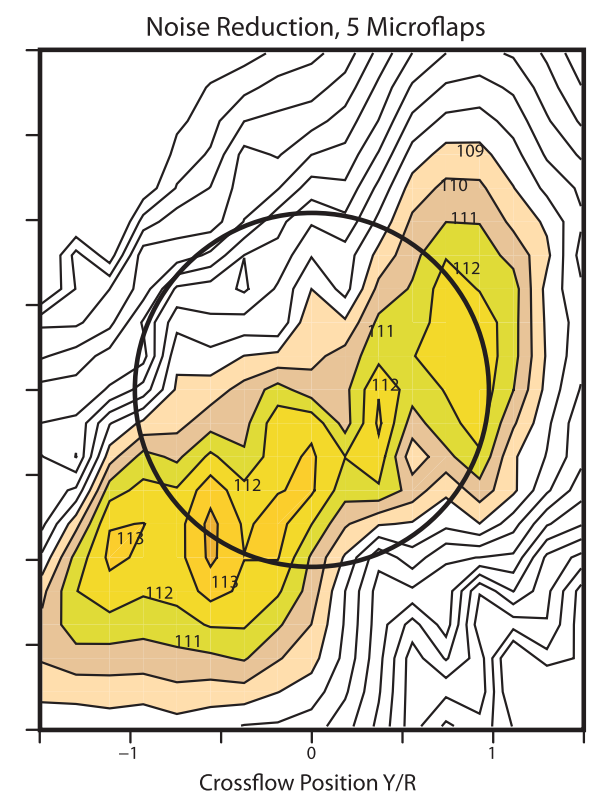

d)

Fig. 14 Noise levels measured on the carpet plane during active noise reduction using microflaps. 


\section{Results and Discussions}

The results presented in this section are obtained for a helicopter configuration resembling a full-scale four-bladed MBB BO-105 hingeless rotor. The rotor parameters are listed in Table 1 . The rotor is trimmed using a propulsive trim procedure. All the values in the table have been nondimensionalized using $M_{b}, L_{b}$, and $1 / \Omega$ for mass, length, and time, respectively. The mass and stiffness distributions are assumed to be constant along the span of the blade. The vibratory hub shears and moments are obtained from the integration of the distributed inertial and aerodynamic loads over the entire blade span in the rotating frame. Subsequently, the loads are transformed to the hub-fixed nonrotating system, and the contributions from the individual blades are combined. In this process, the blades are assumed to be identical. Reduction is performed on the $N_{b} / \mathrm{rev}$ components (which are the dominant components) of the hub shears and moments.

The acoustic environment in the vicinity of the helicopter is characterized by the noise decibel levels computed on a carpet plane located $1.15 R$ beneath the rotor, as depicted in Fig. 9. Various potential locations for placing a feedback microphone on a helicopter, shown in Fig. 9, were examined in [50] for effective BVI noise reduction. A feedback microphone located at the rear of the right skid was found to be most effective for reducing advancing side noise on the carpet plane. This location is used as the feedback microphone location supplying noise output signal to the controller in this study. Another experimental study showing that the skid measurements of BVI noise correlate well with the ground measurements described in $[15,51]$. The sharp trailing-edge configuration, shown in Fig. 10, is chosen for the microflap. The microflap, $1.5 \% \mathrm{c}$ in height, slides in and out of a cavity, located at $6 \% c$ from the sharp trailing edge of the airfoil.

Three different spanwise microflap configurations are considered in this study. The first configuration, shown in Fig. 11a, consists of a single microflap with $0.12 R$ spanwise length centered at $0.75 R$. The second configuration, shown in Fig. 11b, has two microflaps each with $0.06 R$ spanwise length centered at $0.72 R$ and $0.92 R$, respectively. These two configurations are similar to those used in [52] for active control studies using conventional plain flaps. A new configuration used in this study for the microflaps consists of five microflaps each $0.05 R$ in spanwise length placed adjacent to each other, as shown in Fig. 11c. Such a configuration consisting of multiple adjacent microflaps has been used in several microflap application studies mentioned in Sec. I. Active control studies were also conducted using a $20 \% \mathrm{c}$ conventional plain flap, shown in Fig. 12. The single and dual spanwise configurations are considered for the plain flap as shown in Fig. 13.

\section{A. Blade-Vortex Interaction Noise Reduction Using Microflaps}

Noise reduction studies are conducted using the three spanwise microflap configurations for a heavy BVI descending flight condition at an advance ratio of $\mu=0.15$, descent angle $\alpha_{D}=6.5 \mathrm{deg}$, and weight coefficient $C_{W}=0.005$. The adaptive HHC control algorithm is used for noise reduction employing feedback from a microphone located on the right rear skid. The BVI noise contours on the carpet plane are shown in Fig. 14a for the baseline case. The noise levels during active noise reduction using the single, dual, and the five-microflap configurations are shown in Figs. 14b-14d, respectively. The single-microflap configuration yields up to $\overline{3 \mathrm{~dB}}$ noise reduction on the advancing side and $2 \mathrm{~dB}$ reduction on the retreating side of the rotor disk. The dual microflap configuration yields up to $5 \mathrm{~dB}$ noise reduction on the advancing side and close to $3 \mathrm{~dB}$ reduction on the retreating side. Because the single and dual microflap configurations have the same overall microflap span length, it can be concluded that placing the microflap closer to the blade tip is beneficial for noise reduction. The five-microflap configuration reduces the advancing side noise by almost $6 \mathrm{~dB}$ and the retreating side noise by $3 \mathrm{~dB}$. It is interesting to note that the BVI noise is reduced by the microflap configurations for the whole carpet plane; this is in contrast to the earlier active control studies performed using the single and dual conventional ACFs, where no reduction in the retreating side noise levels was observed [19]. The difference between two flaps may be due to the fact that conventional flaps are deployed both downward and upward about the 0 deg position, causing the sectional aerodynamic lift to increase at certain azimuthal locations and decrease at other locations, whereas the microflaps are only deployed downward, resulting only in an increase of sectional lift. A more conclusive explanation would require a detailed study. Overall, significant control authority is demonstrated by the microflaps for rotorcraft noise reduction.

The vibration levels were also monitored during the active noise reduction process. The vibration levels obtained after active noise reduction using the single, dual, and five-microflap configurations are compared to the baseline vibration levels in Fig. 15. The vertical hub shear is increased by $45 \%$ in the case of the single and dual microflap configurations and by $100 \%$ in the case of the fivemicroflap configuration. An increase in vibration levels during active noise reduction was also observed in the earlier active control studies using conventional plain flaps $[19,21]$ as well as in noise control studies using other active control approaches [49]. The microflap deflection histories for the single and dual microflap configurations over one complete revolution are shown in Figs. 16a and $\underline{16 \mathrm{~b}}$. The

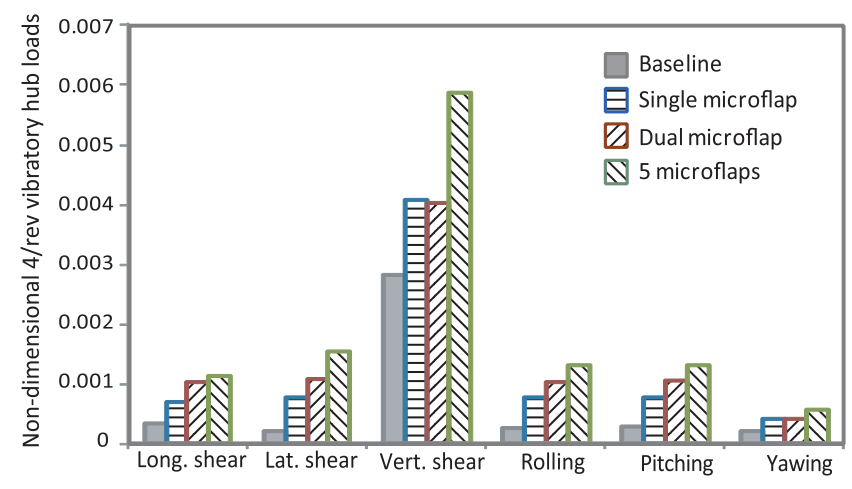

Fig. 15 Vibration levels during active noise reduction using microflaps.

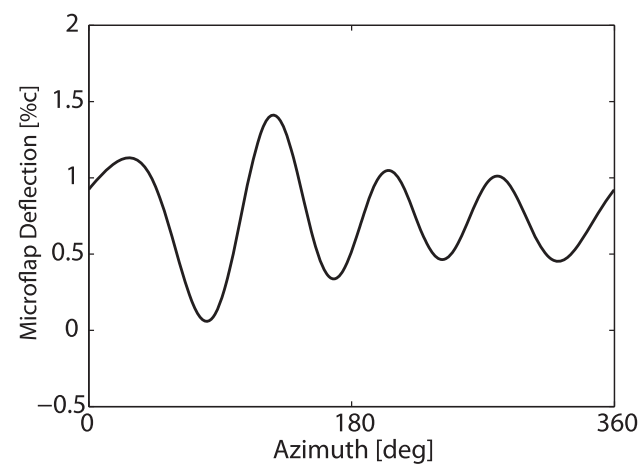

a) Single microflap

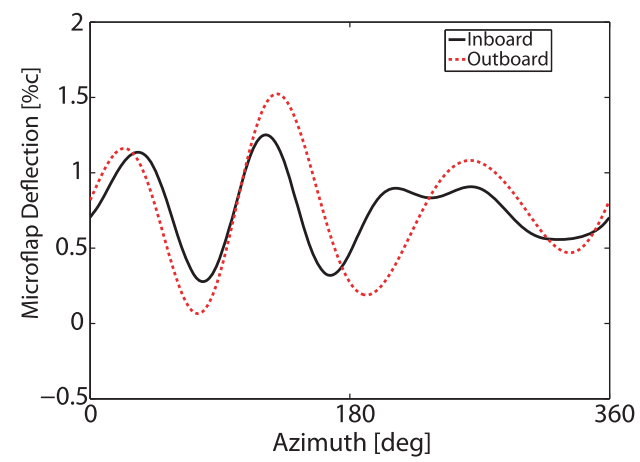

b) Dual microflap

Fig. 16 Microflap deflection histories over one complete revolution for the single and dual microflap configurations during active noise reduction. 


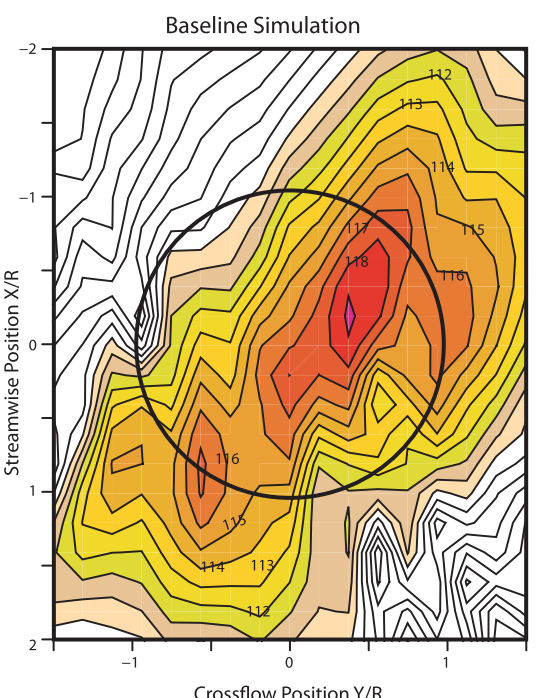

a)

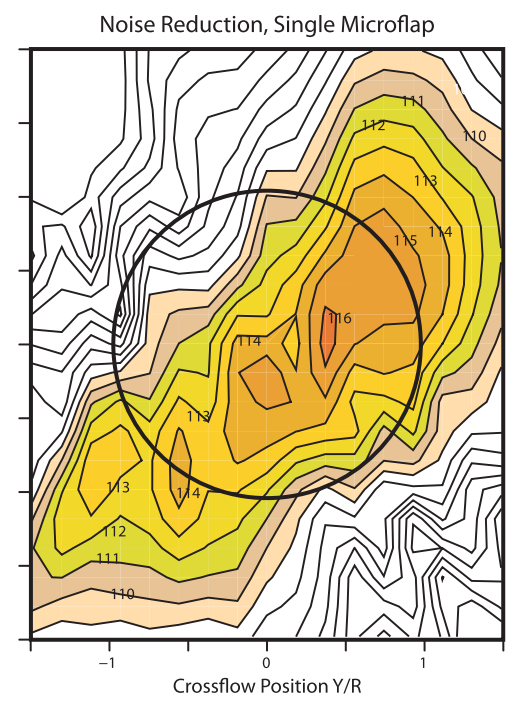

b)

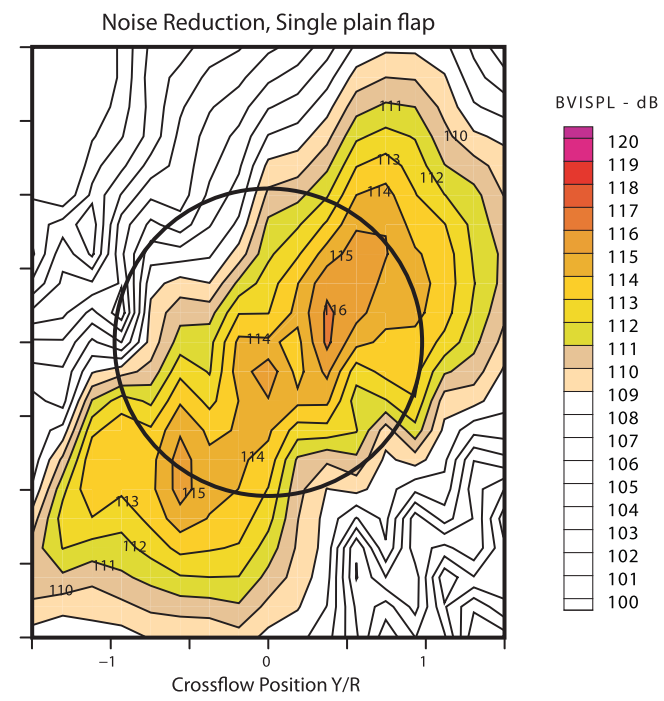

c)

Fig. 17 Comparison of the noise levels measured on the carpet plane during active noise control using a single microflap and a single plain flap.

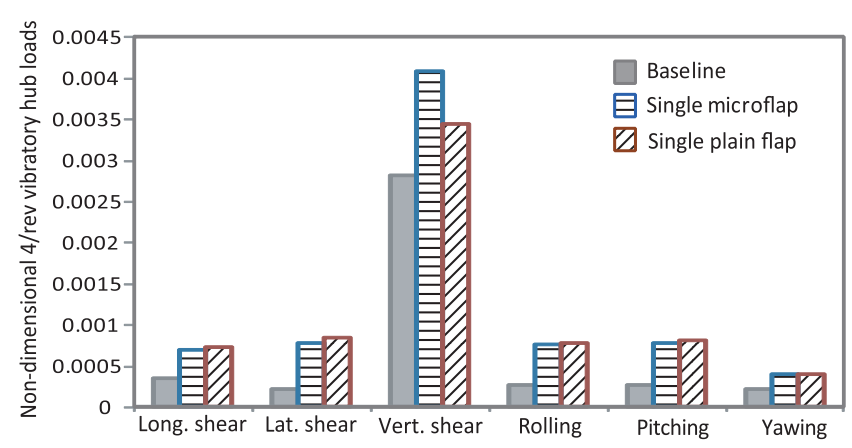

Fig. 18 Comparison of the vibration levels measured during active noise control using a single microflap and a single plain flap.

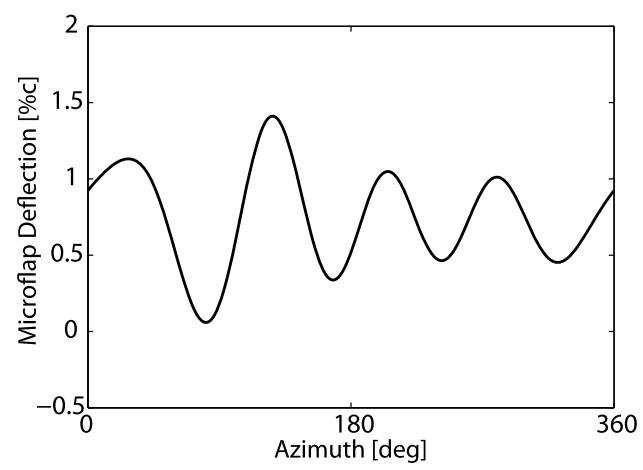

a) Single microflap

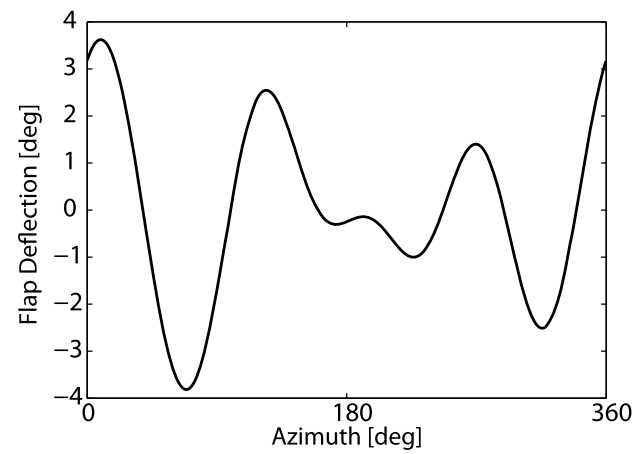

b) Single plain flap

Fig. 19 Microflap deflection histories over one complete revolution for the single microflap and the single plain flap configurations during active noise reduction.

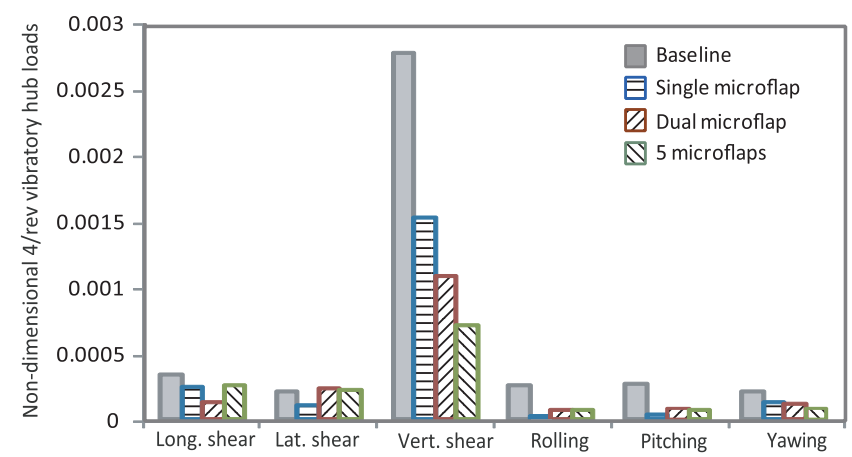

Fig. 20 Reduction in 4/rev vibratory hub shears and moments obtained using the single, dual, and five microflap configurations for a heavy BVI descending flight condition.

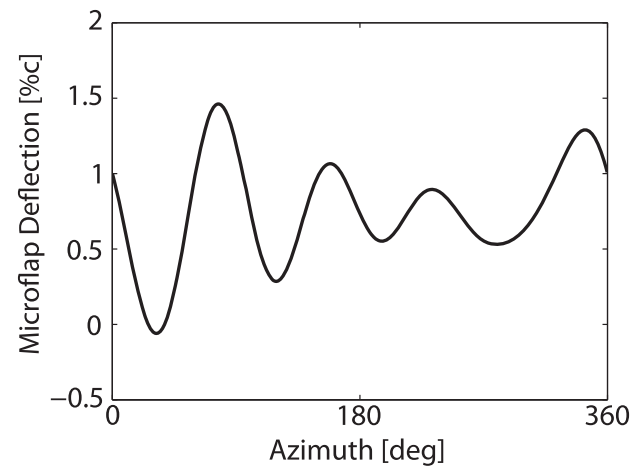

a) Single microflap

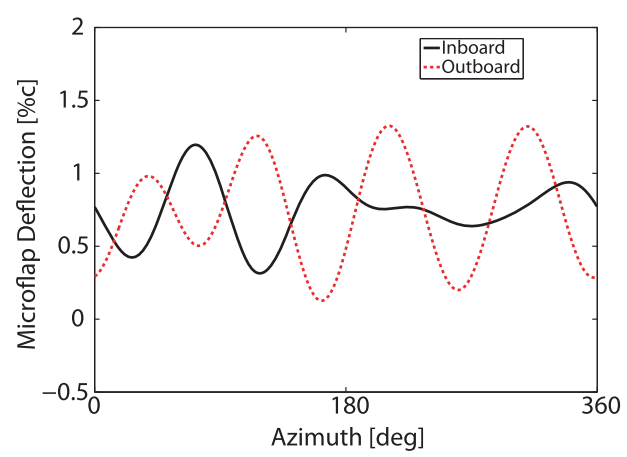

b) Dual microflap

Fig. 21 Microflap deflection histories over one complete revolution for the single and dual microflap configurations during active vibration reduction at BVI flight conditions. 
autoweighting saturation algorithm described in [48] is used to constrain the microflap deflection between 0 and $1.5 \% \mathrm{c}$ that correspond to the retracted and fully deployed positions of the microflap.

Next, the noise reduction capabilities of the microflap are compared to those of a $20 \% c$ trailing-edge plain flap. The plain flap deflections are constrained between $\pm 4 \mathrm{deg}$. The noise levels measured on the carpet plane during active noise control using the single microflap and the single plain flap configurations are shown in Figs. $17 \mathrm{~b}$ and $17 \mathrm{c}$. It is interesting to note that, although the plain flap and the microflap configurations seem to yield similar overall reductions on the advancing side, the single plain flap yields $1 \mathrm{~dB}$ less reduction on the retreating side when compared to the single microflap configuration. The vibration levels measured during active noise control using the single plain flap and the single microflap configurations are compared to the baseline levels in Fig. 18. The vertical hub shear is increased by $45 \%$ in the case of the microflap and by $23 \%$ in the case of the plain flap.
The control surface deflection histories for the single microflap and the single plain flap configurations over one complete revolution are shown in Figs. 19a and 19b, respectively. The flap deflection histories show similar azimuthal locations for the peaks and troughs.

\section{B. Blade-Vortex Interaction Vibration Reduction Using Microflaps}

In this section, vibration reduction with various microflap configurations is examined in the closed-loop mode for the same BVI descending flight condition, with advance ratio $\mu=0.15$ and descent angle $\alpha_{D}=6.5 \mathrm{deg}$. The baseline vibratory hub shears and moments as well as the reduced vibrations obtained using the three microflap configurations are shown in Fig. 20. All three configurations yield a significant reduction in the vibration levels, demonstrating excellent control authority. The single microflap yields a $73 \%$ reduction in the vibration objective, whereas the dual microflap and the five-microflap configurations produce 84 and $92 \%$ reduction, respectively. Note that the vibration objective is a weighted sum of the squares of the $4 / \mathrm{rev}$ vibratory hub shears and moments. The weights used are given in

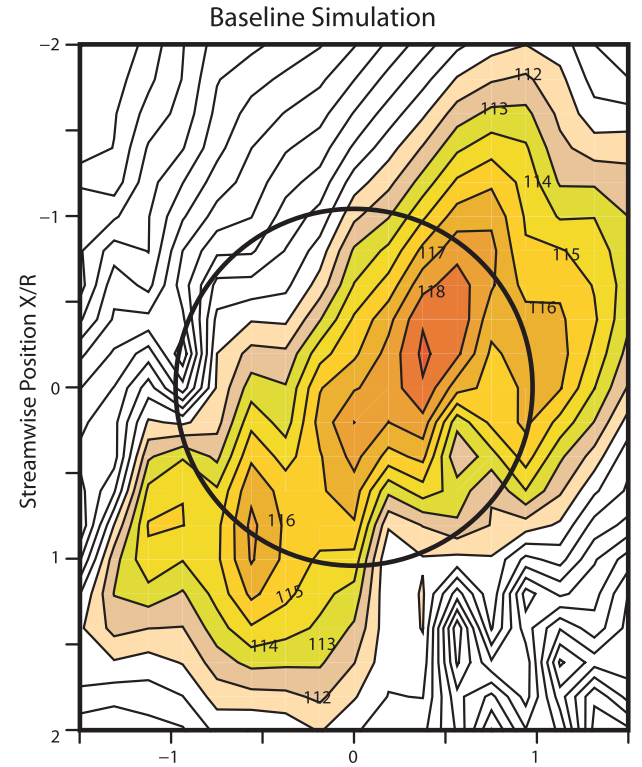

a)

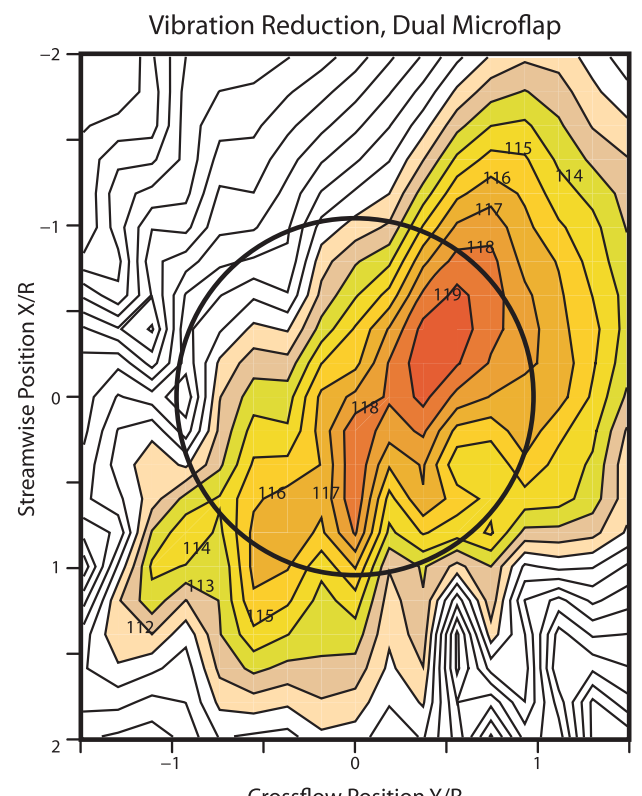

c)

Fig. 22

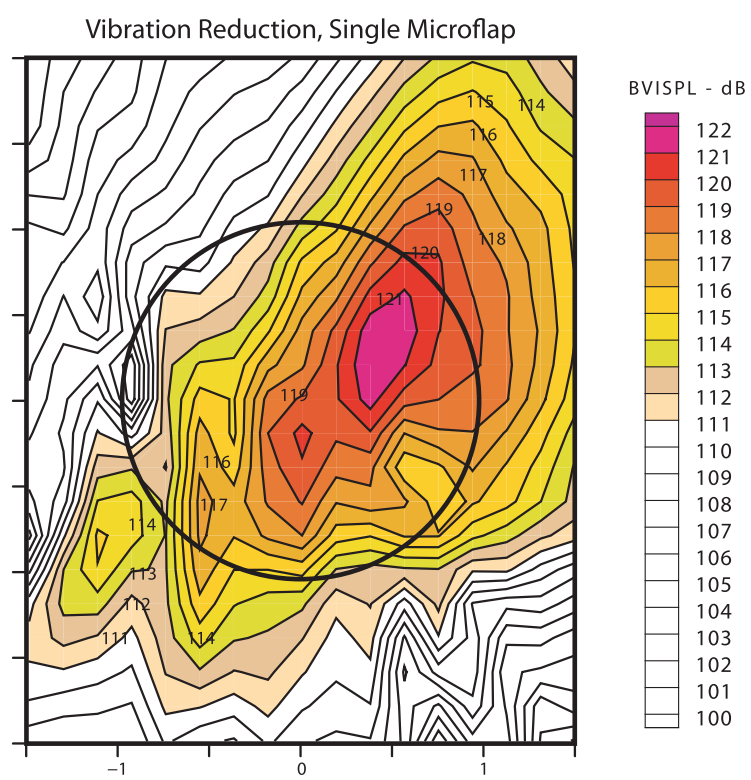

b)

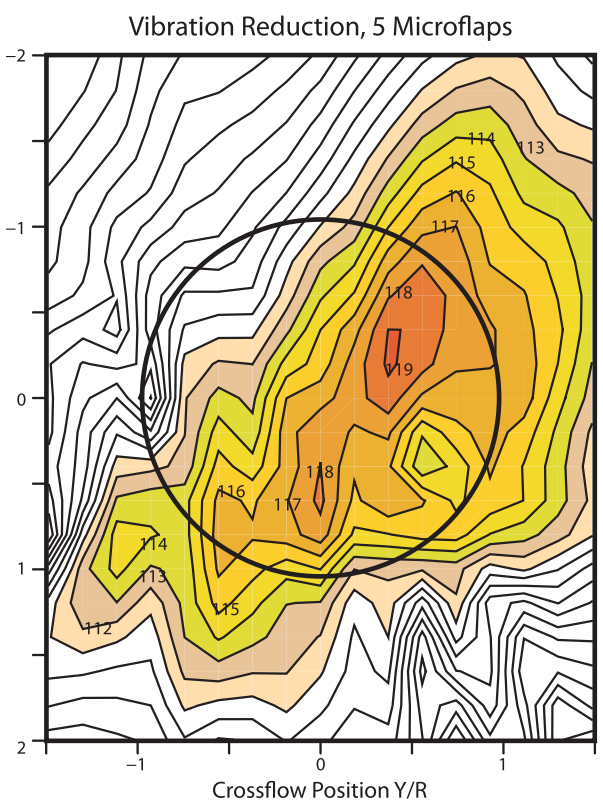

d) 


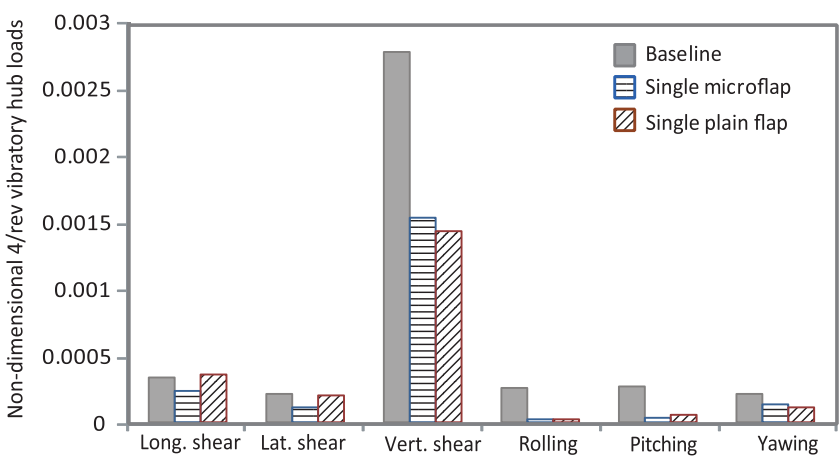

Fig. 23 Comparison of the vibration levels computed during active vibration control using a single microflap and a single plain flap for a heavy BVI descending flight condition.

Eq. (25). The microflap deflection histories for the single and dual microflap configurations over one complete revolution are shown in Figs. 21a and 21b.

Noise levels on the carpet plane were computed during active vibration reduction using microflaps. The noise contours on the carpet plane are shown in Fig. 22a for the baseline case. The noise generated during active vibration reduction using the single, dual, and five-microflap configurations are shown in Figs. 22b-22d, respectively. During vibration reduction, the single microflap generated a significant increase of about $2-3 \mathrm{~dB}$ in the noise levels on the advancing side. By comparison, the dual microflap configuration produced a smaller noise penalty, about $1 \mathrm{~dB}$, on the advancing side. It is very interesting to note that the five-microflap configuration does not produce a noise penalty. The noise levels on the retreating side are not significantly affected by any of the three configurations.

Next, the vibration reduction capabilities of the microflap are compared to those of a $20 \% c$ trailing-edge plain flap. The plain flap deflection is constrained between $\pm 4 \mathrm{deg}$. The $4 / \mathrm{rev}$ vibratory hub loads computed during active vibration control using the single microflap, and the single plain flap configurations are compared to the baseline vibration levels in Fig. 23. The microflap and the plain flap show similar effectiveness, producing 73 and $76 \%$ reductions in the vibration objective, respectively. The noise contours computed on the carpet plane during active vibration control using the single microflap and the single plain flap are shown in Fig. 24. The plain flap causes a $2 \mathrm{~dB}$ increase in the noise levels on the advancing side, whereas the microflap causes up to $3 \mathrm{~dB}$ increase in the advancing side noise levels. Neither of the two flaps shows any significant effect on the retreating side noise levels.

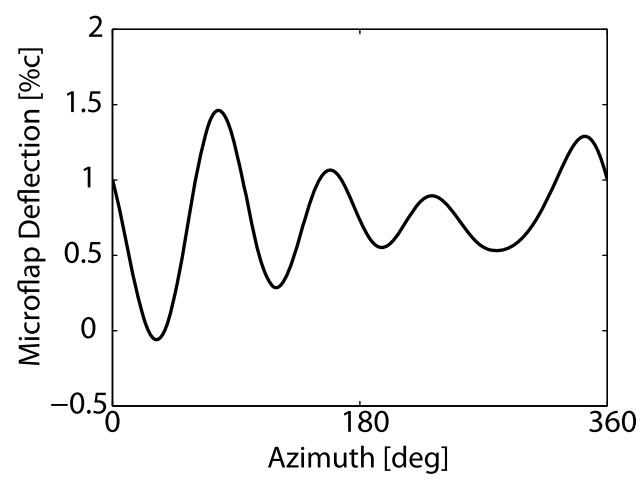

a) Single microflap

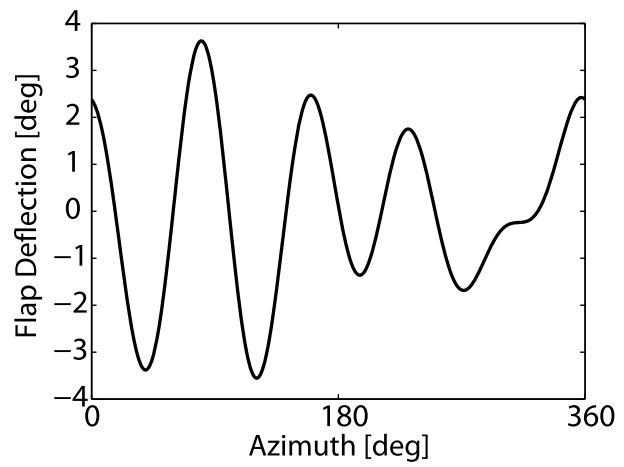

b) Single plain flap

Fig. 25 Deflection histories over one complete revolution for the single microflap and the single plain flap configurations during active vibration reduction at a heavy BVI flight condition.

The control surface deflection histories for the single microflap and the single plain flap configurations over one complete revolution are shown in Figs. 25a and $\underline{25 \mathrm{~b}}$, respectively.

\section{Vibration Reduction at a High Advance Ratio}

In this section, results for vibration reduction with various microflap configurations are presented for a high-speed level cruise flight with $\mu=0.3$ and weight coefficient $C_{W}=0.005$. Vibratory hub loads obtained using the single, dual, and five-microflap configurations are shown in Fig. 26. All three configurations considered here produce a substantial amount of vibration reduction,

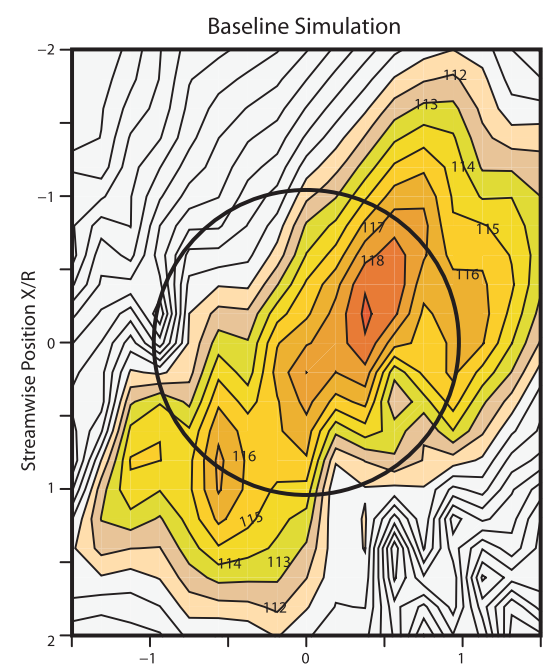

a)

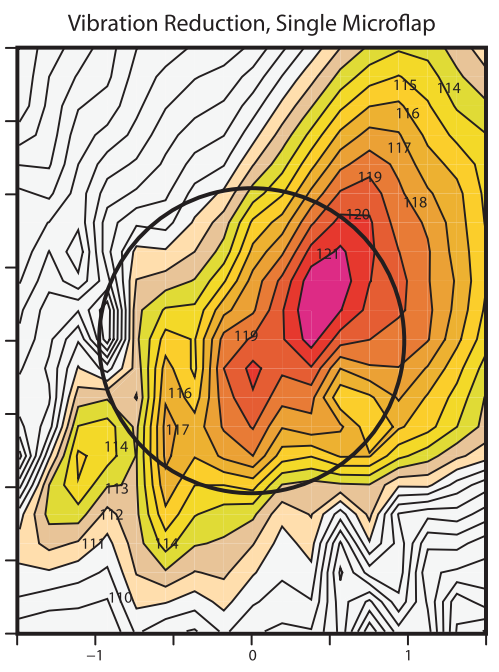

b)

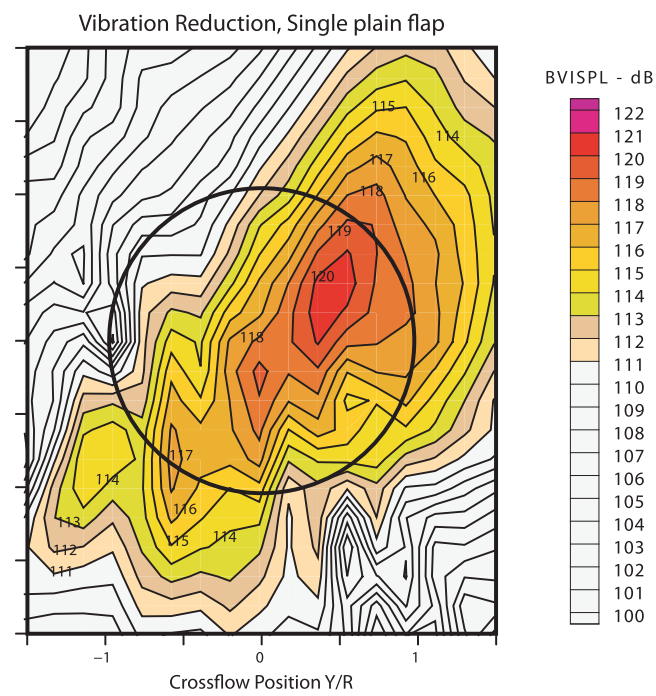

c)

Fig. 24 Comparison of the noise levels computed on the carpet plane during active vibration control using a single microflap and a single plain flap for a heavy BVI descending flight condition. 


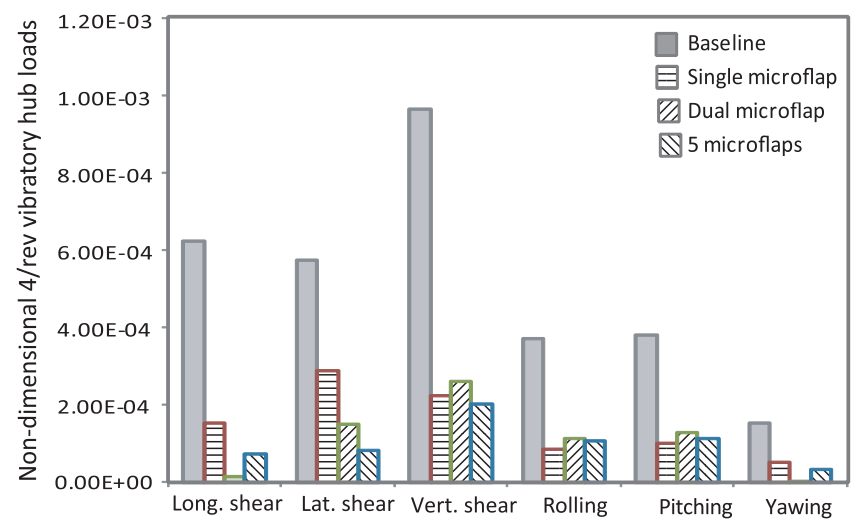

Fig. 26 Reduction in 4/rev vibratory hub shears and moments obtained using the single, dual, and five microflap configurations at a high-speed forward-flight condition.

demonstrating the control authority of the microflap at the high-speed cruise flight condition. The single and dual microflap configurations yield similar reduction levels of $92 \%$ in the vibration objective. The five-microflap configuration also provides a very similar 93\% reduction in the vibration objective. The microflap deflection histories for the single and dual microflap configurations over one complete revolution are shown in Figs. $27 \mathrm{a}$ and $27 \mathrm{~b}$, respectively. The microflap deflection is limited between 0 and $1.5 \% \mathrm{c}$.

Next, the vibration reduction capabilities of the microflap are compared to those of a $20 \%$ c trailing-edge plain flap for this flight condition. Vibration levels obtained using the single and dual flap configurations of the conventional plain flap and the microflap are shown in Fig. 28. The single plain flap and the single microflap configurations yield 94 and $92 \%$ reduction in the vibration objective, respectively. The dual plain flap and the dual microflap configurations yield 96 and $92 \%$ reduction in the vibration objective, respectively. Therefore, the overall vibration reduction levels using the microflaps and conventional flaps are similar. It is also important

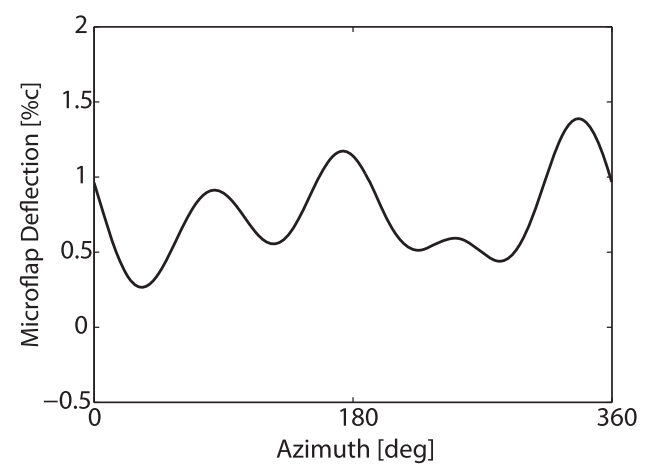

a) Single microflap

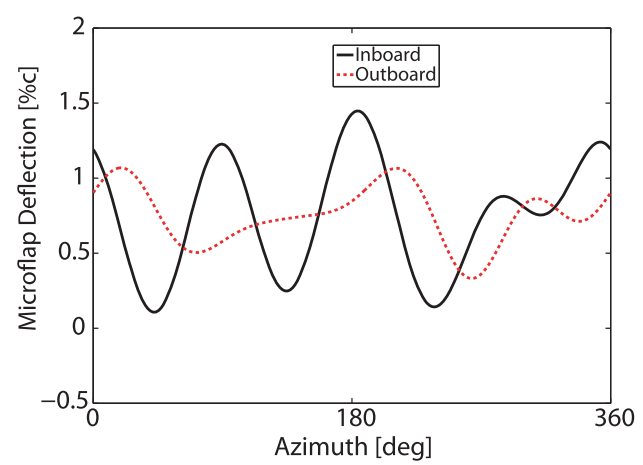

b) Dual microflap

Fig. 27 Microflap deflection histories over one complete revolution for the single and dual microflap configurations during active vibration reduction at a high-speed forward-flight condition.

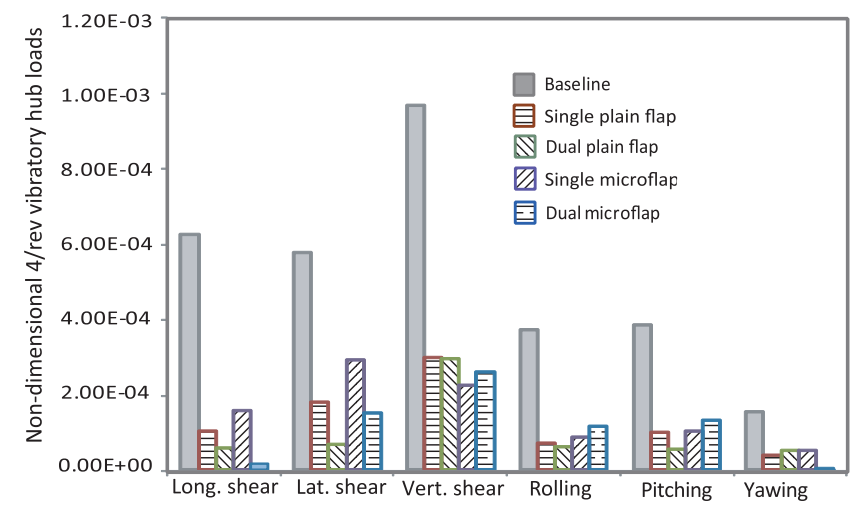

Fig. 28 Reduction of $4 /$ rev vibratory hubloads obtained using the single and dual configurations of the $20 \% c$ trailing-edge plain flap and the $1.5 \% c$ microflap at a high speed condition.

to note that the single and dual microflap configurations incur 3.4 and $5.3 \%$ performance penalties, as evidenced by the increased rotor power requirement, during active vibration reduction at the cruise condition. By comparison, the corresponding plain flap configurations incur less than $1 \%$ performance penalty during vibration reduction. This significant penalty in rotor performance during vibration reduction is a result of higher sectional drag produced by the microflap during its deployment and may be reduced using a smaller microflap deflection (less than 1\%c) [53].

The plain flap deflection histories for the single and dual flap configurations over one complete revolution are shown in Figs. 29a and $29 \mathrm{~b}$, respectively. The angular deflection of the plain flap is restricted to $\pm 4 \mathrm{deg}$ as practical saturation limits. The plain flap deflection histories resemble to the microflap deflection histories (see Fig. 27), where the peaks and troughs of the deflections occur at approximately same azimuthal locations.

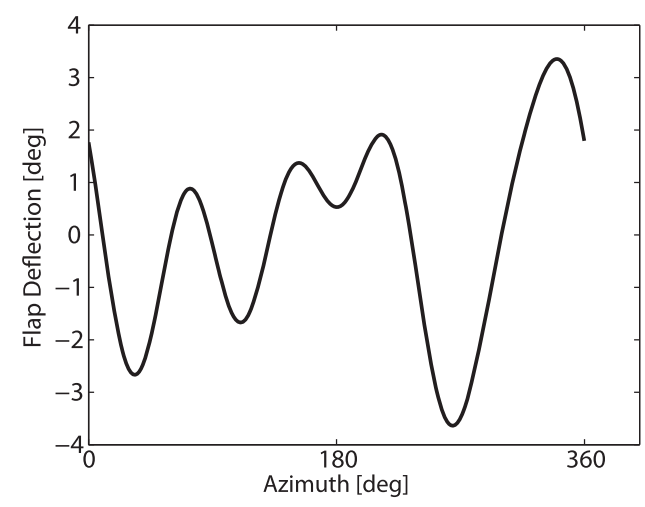

a) Single plain flap

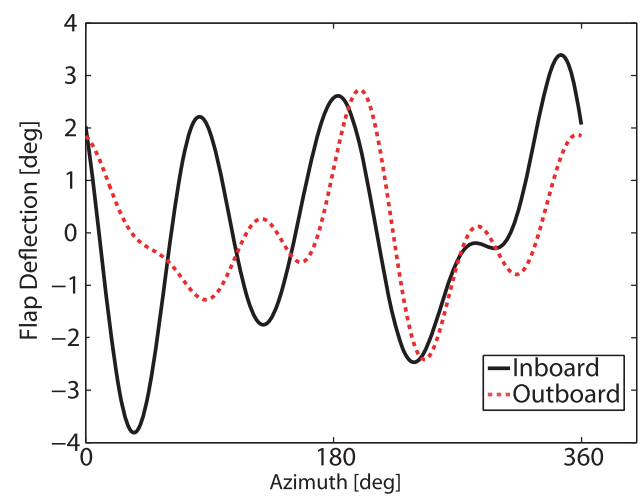

b) Dual plain flap

Fig. 29 Flap deflection histories over one complete revolution for the single and dual plain flap configurations during active vibration reduction at a high-speed forward-flight condition. 
Table 2 Simultaneous reduction of vibratory hubloads and rotor performance using a single microflap

\begin{tabular}{lllllr}
\hline \hline Parameter & \multicolumn{5}{c}{ Values } \\
\hline$W_{\alpha}$ & 0.45 & 0.4 & 0.35 & 0.3 & 0.25 \\
Baseline power & 0.00519928 & 0.00519928 & 0.00519928 & 0.00519928 & 0.00519928 \\
Power after active control & 0.0052977 & 0.00527816 & 0.00521893 & 0.00516958 & 0.00513685 \\
Change in power, $\%$ & 1.89 & 1.51 & 0.37 & -0.57 & -1.2 \\
Change in vibrations, $\%$ & -33 & -8 & 8 & 78 & 171 \\
\hline \hline
\end{tabular}

\section{Performance Enhancement Using Microflaps}

In this section, the effect of microflaps on rotorcraft performance at a high-speed flight condition with $\mu=0.30$ is examined. As was mentioned earlier, vibration reduction using microflaps at a high-speed forward-flight condition results in a significant performance penalty. To further examine the effect of microflaps on rotor performance, closed-loop control studies were conducted with a combined objective function consisting of both vibratory loads and rotor power. The combined output vector in the controller is now defined as

$$
\boldsymbol{z}=\left[\begin{array}{lllllll}
F_{H X 4} & F_{H Y 4} & F_{H Z 4} & M_{H X 4} & M_{H Y 4} & M_{H Z 4} & P_{R}
\end{array}\right]^{T}
$$

The weighting $\boldsymbol{Q}_{z}$ [see Eq. (7)] on the output vector is given by

$$
\boldsymbol{Q}_{z}=\left[\begin{array}{ccccccc}
W_{\alpha} & 0 & 0 & 0 & 0 & 0 & 0 \\
0 & W_{\alpha} & 0 & 0 & 0 & 0 & 0 \\
0 & 0 & W_{\alpha} & 0 & 0 & 0 & 0 \\
0 & 0 & 0 & W_{\alpha} & 0 & 0 & 0 \\
0 & 0 & 0 & 0 & W_{\alpha} & 0 & 0 \\
0 & 0 & 0 & 0 & 0 & W_{\alpha} & 0 \\
0 & 0 & 0 & 0 & 0 & 0 & 1-W_{\alpha}
\end{array}\right]
$$

where the parameter $W_{\alpha}$ is used to vary the relative weighting between the vibratory loads and the rotor power. Note that all the vibratory hub shears and moments are penalized equally. The single microflap configuration is used, and it is employed for control of the combined vibration and power objective. Changes in vibration levels and the corresponding changes in the rotor power obtained for various values of $W_{\alpha}$ are listed in Table 2. The rotor power consumption may be reduced by 0.57 and $1.2 \%$ for $W_{\alpha}$ values of 0.3 and 0.25 , respectively. The reduced power requirement indicates that the microflap has potential as a performance enhancement device. However, the reductions in rotor power consumption are also accompanied by increases in the $4 / \mathrm{rev}$ vibratory hub loads by 78 and $171 \%$, respectively, as shown in the table. The vibratory hub loads corresponding to the various values of $W_{\alpha}$ are shown in Fig. 30. The longitudinal and lateral shear forces are significantly increased during performance enhancement, particularly for the relative weight $W_{\alpha}=0.25$. Furthermore, for the single microflap configuration considered here, simultaneous vibration reduction and performance enhancement was not found.

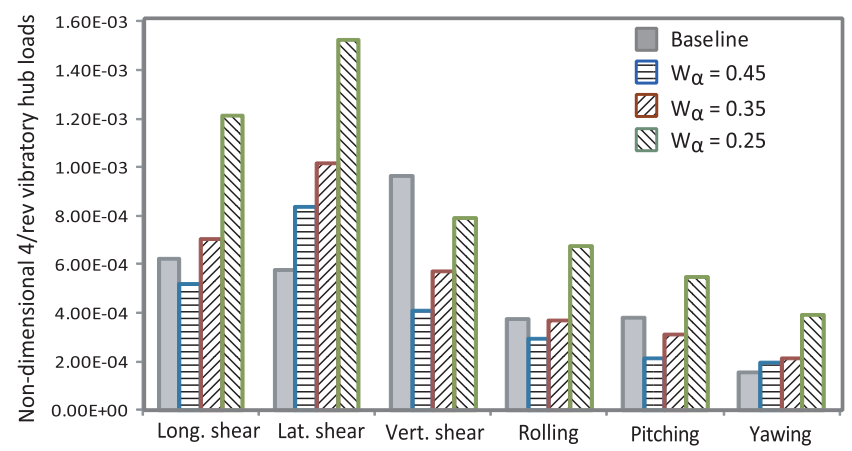

Fig. 30 Effect of a single microflap on the vibratory hub loads during active control of vibrations and rotor performance using a combined objective function.

\section{E. Effect of Microflap Chordwise Location}

The effect of chordwise location of the microflap on its vibration reduction performance was also studied. A microflap located at $10 \% \mathrm{c}$ from the airfoil trailing edge, as shown in Fig. 31, is compared to the original microflap located at $6 \% c$. The height of the microflap is unchanged at $1.5 \% \mathrm{c}$. Data required for the RFA model were generated for the new $10 \% c$ microflap using CFD++. Note that the unsteady data corresponding to only the $D_{0}$ generalized motion need to be generated.

Vibration reduction performance of a single $10 \% \mathrm{c}$ microflap is compared to a single 6\% microflap in Fig. 32. These results are obtained at the BVI descending flight condition. The $10 \% \mathrm{c}$ microflap yields $54 \%$ reduction in the vibration objective compared to $64 \%$ by the $6 \% c$ microflap. The aerodynamic effectiveness of the microflap decreases with an increasing distance from the trailing edge $[3,5]$. Figure 33 shows a comparison of the unsteady lift and moment generated by the two different microflap configurations at $M=0.6$, $\alpha=0 \mathrm{deg}$, and reduced frequency of microflap oscillation $k=0.02$. The difference in the unsteady lift amplitude is small, whereas the difference in moment is significant. The unsteady moment generated by the microflap at $6 \% \mathrm{c}$ is $16 \%$ more than that generated by the microflap at $10 \% c$; thus, the former has better control authority for vibration reduction.

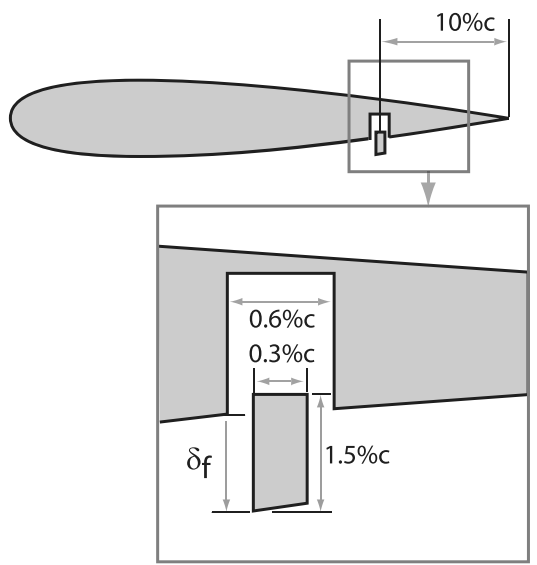

Fig. 31 Oscillating microflap located at $10 \% c$ from the trailing edge.

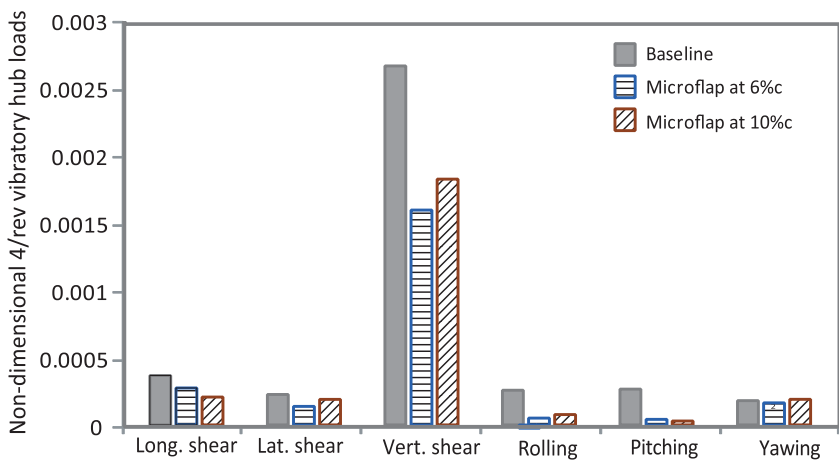

Fig. 32 Comparison of the vibration levels computed during active vibration control using single microflaps located at 6 and $10 \% c$ from the trailing edge, respectively. 


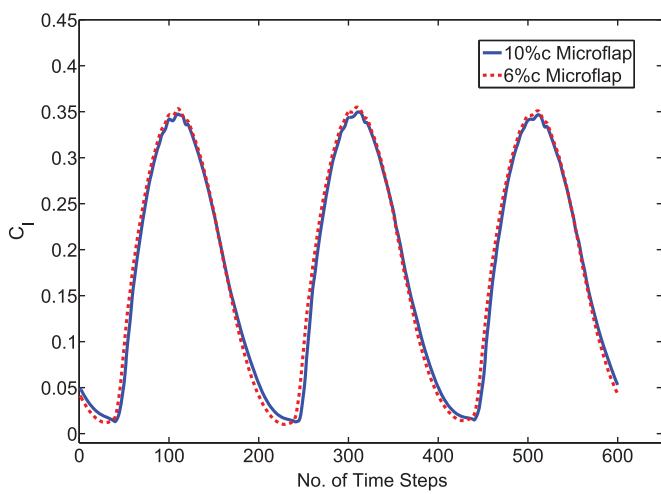

a) Lift

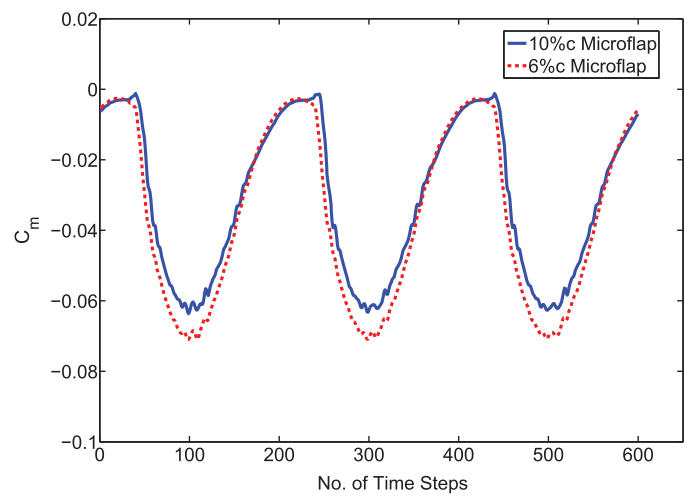

b) Moment

Fig. 33 Comparison of unsteady lift and moment generated by the 6 and $10 \% c$ microflaps at $M=0.6, \alpha=0$ deg, and reduced frequency of microflap oscillation $k=0.02$.

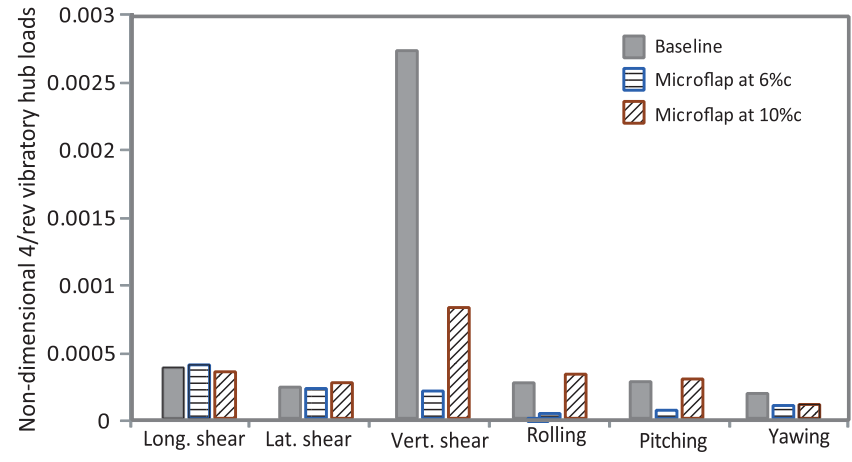

Fig. 34 Comparison of the vibration levels computed during active vibration control using the 6 and $10 \% c$ microflaps in the dual spanwise configuration.

Vibration reduction performance of the $10 \% \mathrm{c}$ microflap and the $6 \% c$ microflap in the dual spanwise configuration is compared in Fig. 34. The dual $10 \% \mathrm{c}$ microflap configuration yields $86 \%$ reduction in the vibration objective compared to $96 \%$ by the dual $6 \% \mathrm{c}$ microflap configuration. The trends are similar to those observed for the single microflap configuration.

\section{Conclusions}

The control authority of microflaps for on-blade control of noise and vibration in rotorcraft was examined. A comprehensive rotorcraft simulation code AVINOR was employed, which captures the aerodynamic effects of a microflap using a CFD-based reduced-order aerodynamic model. Based on earlier research, a sliding microflap configuration with a $1.5 \% \mathrm{c}$ height was selected for active control studies. Three spanwise microflap configurations are considered: single, dual, and a segmented five-flap configuration. The adaptive HHC control algorithm was employed for active noise and vibration reduction studies in closed loop. Active noise reduction using the microflaps was examined under a heavy BVI descending flight condition with the advance ratio $\mu=0.15$ and descent angle $\alpha_{D}=6.5 \mathrm{deg}$. Active vibration reduction was also examined at the BVI descending flight condition and a high-speed cruise flight condition. The principal findings of the study are summarized next.

1) The microflap's effectiveness in reducing BVI noise was demonstrated. Depending on the configuration, 3-6 dB noise reduction was achieved on the advancing side, and $2-3 \mathrm{~dB}$ reduction was shown on the retreating side.

2) It was also found that active noise reduction using microflaps produced an increase in the $4 / \mathrm{rev}$ vertical rotor hub shears. The single and dual microflap configurations caused a $45 \%$ increase in the vertical shear, whereas the five-microflap configuration resulted in a $100 \%$ increase in the vertical shear. A similar trend was identified computationally and experimentally with other active control approaches such as the conventional HHC and the ACF [19,21,49].

3) The single $1.5 \% \mathrm{c}$ microflap was compared and found to resemble in its effectiveness a single $20 \%$ c plain flap for noise reduction. Although both devices yield similar reduction levels on the advancing side, the microflap yields $1 \mathrm{~dB}$ higher reduction on the retreating side.

4) Active vibration reduction was demonstrated using the microflap under heavy BVI descending flight condition. The single, dual, and five-microflap configurations produced 73,84 , and $92 \%$ reduction in the vibration objective, respectively, demonstrating very good control authority for rotorcraft vibration reduction. However, vibration reduction using a single microflap configuration produced a 2-3 dB noise penalty on the carpet plane. This penalty was reduced for the dual and five-microflap configurations.

5) The single $1.5 \% \mathrm{c}$ microflap and the single $20 \% \mathrm{c}$ plain flap configuration show similar effectiveness in vibration reduction capabilities, producing 73 and $76 \%$ reduction in the vibration objective, respectively.

6) Vibration reduction was examined for a high-speed cruise flight condition at $\mu=0.3$. All three microflap configurations produced over $90 \%$ reduction in the vibration objective. Similar vibration reduction levels were obtained using the microflaps and the conventional plain flaps.

7) The microflaps were also considered for rotor performance enhancement at the high-speed forward-flight condition with $\mu=0.3$, using closed-loop control with combined vibration and rotor power objectives. Although a $1.2 \%$ performance enhancement was obtained using the single microflap configuration, it was accompanied by a $170 \%$ increase in the vibration objective.

8) Changing the microflap location relative to the trailing edge from 6 to $10 \% c$ decreases the vibration reduction performance by $10 \%$. This is a result of a decrease in the aerodynamic effectiveness of the microflap as it is moved away from the trailing edge.

These conclusions demonstrate the effectiveness and control authority of the microflap for multiobjective control in rotorcraft and establish the microflap as a viable active device for on-blade control.

\section{Acknowledgments}

This research was supported by the Vertical Lift Research Center of Excellence sponsored by National Rotorcraft Technology Center and the U.S. Army.

\section{References}

[1] Liebeck, R. H., "Design of Subsonic Airfoils for High Lift," Journal of Aircraft, Vol. 52, No. 6, Sept. 1978, pp. 547-561. doi: $10.2514 / 3.58406$

[2] Storms, B. L., and Jang, C. S., "Lift Enhancement of an Airfoil Using a Gurney Flap and Vortex Generators," Journal of Aircraft, Vol. 31, No. 3, May-June 1994, pp. 542-547. doi: $10.2514 / 3.46528$ 
[3] Baker, J. P., Standish, K. J., and van Dam, C. P., "Two-Dimensional Wind Tunnel and Computational Investigation of a Microtab Modified Airfoil," Journal of Aircraft, Vol. 44, No. 2, March-April 2007, pp. 563-572. doi: $10.2514 / 1.24502$

[4] Maughmer, M. D., and Bramesfeld, G., "Experimental Investigation of Gurney Flaps," Journal of Aircraft, Vol. 45, No. 6, Nov.-Dec. 2008, pp. 2062-2067. doi: $10.2514 / 1.37050$

[5] Giguere, P., Lemay, J., and Dumas, G., "Gurney Flap Effects and Scaling for Low-Speed Airfoils," 13th Applied Aerodynamics Conference, AIAA Paper 1995-1881, June 1995.

[6] Jang, C. S., Ross, J. C., and Cummings, R. M., "Numerical Investigation of an Airfoil with a Gurney Flap," Journal of Aircraft Design, Vol. 1, No. 2, June 1998, pp. 75-88. doi:10.1016/S1369-8869(98)00010-X

[7] Chow, R., and van Dam, C. P., "Unsteady Computational Investigations of Deploying Load Control Microtabs," Journal of Aircraft, Vol. 43, No. 5, Sept.-Oct. 2006, pp. 1458-1469. doi: $10.2514 / 1.22562$

[8] Lee, H.-T., Kroo, I. M., and Bieniawski, S., "Flutter Suppression for High Aspect Ratio Flexible Wings Using Microflaps," 43rd AIAA/ ASME/ASCE/AHS/ACS Structures, Structural Dynamics and Materials Conference, AIAA Paper 2002-1717, April 2002.

[9] Kroo, I. M., "Aerodynamic Concepts for Future Aircraft," 30th AIAA Fluid Dynamics Conference, AIAA Paper 1999-2003, JuneJuly 1999.

[10] Matalanis, C. G., and Eaton, J. K., "Wake Vortex Alleviation Using Rapidly Actuated Segmented Gurney Flaps," AIAA Journal, Vol. 45, No. 8, Aug. 2007, pp. 1874-1884. doi:10.2514/1.28319

[11] Vey, S., Paschereit, O. C., Greenblatt, D., and Meyer, R., "Flap Vortex Management by Active Gurney Flaps," 46th AIAA Aerospace Sciences Meeting and Exhibit, AIAA Paper 2008-286, Jan 2008.

[12] Nikolic, V. R., "Two Aspects of the Use of Full- and Partial-Span Gurney Flaps," Journal of Aircraft, Vol. 44, No. 5, Sept.-Oct. 2007, pp. 17451748.

doi: $10.2514 / 1.29136$

[13] Nakafuji, D. T. Y., van Dam, C. P., Smith, R. L., and Collins, S. D., "Active Load Control for Airfoils Using Microtabs," Journal of Solar Energy Engineering, Vol. 123, No. 4, Nov. 2001, pp. 282-289. doi: $10.1115 / 1.1410110$

[14] Wilson, D. G., Berg, D. E., Li, D. W., and Zayas, J. R., "Optimized Active Aerodynamic Blade Control for Load Alleviation on Large Wind Turbines," Proceedings of the AWEA WINDPOWER 2008 Conference and Exhibition, Houston, TX, June 2008.

[15] Friedmann, P. P., "On-Blade Control of Rotor Vibration, Noise, and Performance: Just Around the Corner?" Journal of American Helicopter Society, Vol. 59, No. 4, July 2014, pp. 1-37. doi:10.4050/JAHS.59.041001

[16] Friedmann, P. P., and Millott, T. A., "Vibration Reduction in Rotorcraft Using Active Control: A Comparison of Various Approaches," Journal of Guidance, Control, and Dynamics, Vol. 18, No. 4, July-Aug. 1995, pp. 664-673.

doi: $10.2514 / 3.21445$

[17] Friedmann, P. P., de Terlizzi, M., and Myrtle, T. F., "New Developments in Vibration Reduction with Actively Controlled Trailing Edge Flaps," Mathematical and Computer Modelling, Vol. 33, Nos. 10-11, 2001, pp. 1055-1083. doi:10.1016/S0895-7177(00)00300-9

[18] Koratkar, N. A., and Chopra, I., "Wind Tunnel Testing of a Smart Rotor Model with Trailing Edge Flaps," Journal of the American Helicopter Society, Vol. 47, No. 4, Oct. 2002, pp. 263-272. doi:10.4050/JAHS.47.263

[19] Patt, D., Liu, L., and Friedmann, P. P., "Simultaneous Vibration and Noise Reduction in Rotorcraft Using Aeroelastic Simulation," Journal of the American Helicopter Society, Vol. 51, No. 2, April 2006, pp. 127-140. doi:10.4050/JAHS.51.127

[20] Roth, D., Enenkl, B., and Dieterich, O., "Active Rotor Control by Flaps for Vibration Reduction - Full Scale Demonstrator and First Flight Test Results," Proceedings of the 32nd European Rotorcraft Forum, Maastricht, The Netherlands, Sept. 2006.

[21] Straub, F. K., Anand, V. R., Birchette, T. S., and Lau, B. H., "Wind Tunnel Test of the SMART Active Flap Rotor," Proceedings of the 65th Annual AHS Forum, Grapevine, TX, May 2009.

[22] Liu, L., Friedmann, P. P., Kim, I., and Bernstein, D. S., "Rotor Performance Enhancement and Vibration Reduction in Presence of Dynamic Stall Using Actively Controlled Flaps," Journal of the
American Helicopter Society, Vol. 53, No. 4, Oct. 2008, pp. 338-350. doi:10.4050/JAHS.53.338

[23] Glaz, B., Friedmann, P. P., and Liu, L., "Vibration Reduction and Performance Enhancement of Helicopter Rotors Using an Active/ Passive Approach," 49th AIAA/ASME/ASCE/AHS/ACS Structures, Structural Dynamics and Materials Conference, AIAA Paper 20082178, April 2008.

[24] Glaz, B., Friedmann, P. P., Liu, L., Kumar, D., and Cesnik, C. E. S., "The AVINOR Aeroelastic Simulation Code and Its Application to Reduced Vibration Composite Rotor Blade Design," 50th AIAA/ASME/ASCE/ AHS/ACS Structures, Structural Dynamics and Materials Conference, AIAA Paper 2009-2601, May 2009.

[25] Brentner, K., "A Computer Program Incorporating Realistic Blade Motions and Advanced Acoustic Formulation," NASA TM-87721, Oct. 1986.

[26] Roget, B., and Chopra, I., "Closed-Loop Test of a Rotor with Individually Controlled Trailing-Edge Flaps for Vibration Reduction," Journal of the American Helicopter Society, Vol. 55, No. 1, Jan. 2010, pp. 012009-1-012009-12. doi:10.4050/JAHS.55.012009

[27] Kinzel, M. P., Maughmer, M. D., Lesieutre, G. L., and Duque, E. P. N., "Numerical Investigation of Miniature Trailing-Edge Effectors on Static and Oscillating Airfoils," 43rd AIAA Aerospace Sciences Meeting and Exhibit, AIAA Paper 2005-1039, Jan. 2005.

[28] Kinzel, M. P., Maughmer, M. D., and Lesieutre, G. L., "Miniature Trailing-Edge Effectors for Rotorcraft Performance Enhancement," Journal of the American Helicopter Society, Vol. 52, No. 2, April 2007, pp. 146-158. doi:10.4050/JAHS.52.146

[29] Kinzel, M. P., Maughmer, M. D., and Duque, E. P. N., "Numerical Investigation on the Aerodynamics of Oscillating Airfoils with Deployable Gurney Flaps," AIAA Journal, Vol. 48, No. 7, July 2010, pp. $1457-1469$. doi:10.2514/1.J050070

[30] Min, B. Y., Sankar, L., and Bauchau, O. A., "A CFD-CSD Coupled Analysis of Hart II Rotor Vibration Reduction Using Gurney Flaps," Proceedings of the 66th American Helicopter Society Annual Forum, Phoenix, AZ, May 2010.

[31] Liu, L., Padthe, A. K., and Friedmann, P. P., "Computational Study of Microflaps with Application to Vibration Reduction in Helicopter Rotors," AIAA Journal, Vol. 49, No. 7, July 2011, pp. 1450-1465. doi:10.2514/1.J050829

[32] Warwick, G., "Racing Inspired: It Worked for Indy Cars, Now the Gurney Flap Could be a Key to Better Helicopter Rotors," Aviation Week and Space Technology, March 2014, p. 16.

[33] Liu, L., Padthe, A., Friedmann, P. P., Quon, E., and Smith, M., "Unsteady Aerodynamics of an Airfoil/Flap Combination on a Helicopter Rotor Using CFD and Approximate Methods," Journal of American Helicopter Society, Vol. 56, No. 3, July 2011, pp. 032003-1032003-13. doi:10.4050/JAHS.56.032003

[34] Rogers, K. L., "Airplane Math Modeling Methods for Active Control Design," AGARD CP-228, Neuilly sur Seine, France, Aug. 1977.

[35] Edwards, J. H., "Application of Laplace Transform Methods to Airfoil Motion and Stability Calculations," 20th Structures, Structural Dynamics and Materials Conference, AIAA Paper 1979-0772, April 1979.

[36] Karpel, M., "Design for Active and Passive Flutter Suppression and Gust Alleviation," NASA CR-3492, Nov. 1981.

[37] Vepa, R., "Finite State Modeling of Aeroelastic Systems," NASA CR2779, Feb. 1977.

[38] Myrtle, T. F., and Friedmann, P. P., "Application of a New Compressible Time Domain Aerodynamic Model to Vibration Reduction in Helicopters Using an Actively Controlled Flap," Journal of the American Helicopter Society, Vol. 46, No. 1, Jan. 2001, pp. 32-43. doi:10.4050/JAHS.46.32

[39] Peroomian, O., Chakravarthy, S., Palaniswamy, S., and Goldberg, U., "Convergence Acceleration for Unified-Grid Formulation Using Preconditioned Implicit Relaxation," 36th AIAA Aerospace Sciences Meeting and Exhibit, AIAA Paper 1998-0116, Jan. 1998.

[40] Peroomian, O., Chakravarthy, S., and Goldberg, U., "A 'GridTransparent' Methodology for CFD," 35th Aerospace Sciences Meeting and Exhibit, AIAA Paper 1997-0724, Jan. 1997.

[41] Boor, C. D., A Practical Guide to Splines, Springer-Verlag, New York, 2001, pp. 40-47.

[42] Kahaner, D., Moler, C., and Nash, S., Numerical Methods and Software, Prentice-Hall, Upper Saddle River, NJ, 1989, pp. 100-106.

[43] Press, W. H., Flannery, B. P., Teukolsky, S. A., and Vetterling, W. T., Numerical Recipes in FORTRAN 77, Cambridge Univ. Press, Cambridge, England, U.K., 1992, pp. 107-110. 
[44] de Terlizzi, M., and Friedmann, P. P., "Active Control of BVI Induced Vibrations Using a Refined Aerodynamic Model and Experimental Correlation," Proceedings of the American Helicopter Society 55th Annual Forum, American Helicopter Soc. International, Fairfax, VA, May 1999, pp. 599-615.

[45] Patt, D., Liu, L., and Friedmann, P. P., "Rotorcraft Vibration Reduction and Noise Prediction Using a Unified Aeroelastic Response Simulation," Journal of the American Helicopter Society, Vol. 50, No. 1, Jan. 2005, pp. 95-106. doi:10.4050/1.3092846

[46] Abbott, I. H., Doenhoff, A. E. V., and Stivers, L. S., "Summary of Airfoil Data," NACA Rept. 824, Jan. 1945.

[47] Patt, D., Liu, L., Chandrasekar, J., Bernstein, D. S., and Friedmann, P. P., "Higher-Harmonic-Control Algorithm for Helicopter Vibration Reduction Revisited," Journal of Guidance, Control, and Dynamics, Vol. 28, No. 5, Sept.-Oct. 2005, pp. 918-930. doi: $10.2514 / 1.9345$

[48] Cribbs, R., and Friedmann, P. P., "Actuator Saturation and Its Influence on Vibration Reduction by Actively Controlled Flaps," 42nd AIAA/ ASME/ASCE/AHS/ACS Structures, Structural Dynamics and Materials Conference, AIAA Paper 2001-1467, April 2001.
[49] Splettstoesser, W., Kube, R., Wagner, W., Seelhorst, U., Boutier, A. Micheli, F., Mercker, E., and Pengel, K., "Key Results From a Higher Harmonic Control Aeroacoustic Rotor Test (HART)," Journal of the American Helicopter Society, Vol. 42, No. 1, Jan. 1997, pp. 58-78. doi:10.4050/JAHS.42.58

[50] Liu, L., "BVI Induced Vibration and Noise Alleviation by Active and Passive Approaches," Ph.D. Thesis, Univ. of Michigan, Ann Arbor, MI, 2005.

[51] Bebesel, M., Roth, D., and Pongratz, K., "Reduction of BVI Noise on the Ground-In Flight Evaluation of Closed-Loop Controller," Proceedings of the 28th European Rotorcraft Forum, Bristol, England, U.K., Sept. 2002.

[52] Myrtle, T. F., "Development of an Improved Aeroelastic Model for the Investigation of Vibration Reduction in Helicopter Rotors Using Trailing Edge Flaps," Ph.D. Thesis, Univ. of California, Los Angeles, 1998.

[53] Padthe, A. K., Liu, L., and Friedmann, P. P., "A Comprehensive Study of Active Microflaps for Vibration Reduction in Rotorcraft," Proceedings of the 66th American Helicopter Society Annual Forum, Phoenix, AZ, May 2010. 